\title{
An Intact Dilysine-like Motif in the Carboxyl Terminus of MAL Is Required for Normal Apical Transport of the Influenza Virus Hemagglutinin Cargo Protein in Epithelial Madin-Darby Canine Kidney Cells
}

\author{
Rosa Puertollano, ${ }^{*+}$ José Angel Martínez-Menárguez, ${ }^{\ddagger \dagger}$ Alicia Batista, ${ }^{*}$ \\ José Ballesta, ${ }^{\ddagger}$ and Miguel Angel Alonso*§
}

\author{
*Centro de Biología Molecular "Severo Ochoa," Universidad Autónoma de Madrid, and Consejo \\ Superior de Investigaciones Científicas, Cantoblanco, 28049-Madrid, Spain; and ‡Departamento de \\ Biología Celular, Facultad de Medicina, Universidad de Murcia, 30071-Murcia, Spain
}

Submitted June 14, 2000; Revised February 27, 2001; Accepted April 2, 2001

Monitoring Editor: Suzanne R. Pfeffer

\begin{abstract}
The MAL proteolipid, a component of the integral protein sorting machinery, has been demonstrated as being necessary for normal apical transport of the influenza virus hemagglutinin (HA) and the overall apical membrane proteins in Madin-Darby canine kidney (MDCK) cells. The MAL carboxy terminus ends with the sequence Arg-Trp-Lys-Ser-Ser (RWKSS), which resembles dilysine-based motifs involved in protein sorting. To investigate whether the RWKSS pentapeptide plays a role in modulating the distribution of MAL and/or its function in apical transport, we have expressed MAL proteins with distinct carboxy terminus in MDCK cells whose apical transport was impaired by depletion of endogenous MAL. Apical transport of HA was restored to normal levels by expression of MAL with an intact but not with modified carboxyl terminal sequences bearing mutations that impair the functioning of dilysine-based sorting signals, although all the MAL proteins analyzed incorporated efficiently into lipid rafts. Ultrastructural analysis indicated that compared with MAL bearing an intact RWKSS sequence, a mutant with lysine -3 substituted by serine showed a twofold increased presence in clathrin-coated cytoplasmic structures and a reduced expression on the plasma membrane. These results indicate that the carboxyl-terminal RWKSS sequence modulates the distribution of MAL in clathrin-coated elements and is necessary for HA transport to the apical surface.
\end{abstract}

\section{INTRODUCTION}

It has been suggested that internal glycolipid and cholesterol-enriched membrane (GEM) rafts resistant to detergent solubilization play a role in vectorial transport of proteins to the apical surface in polarized epithelial Madin-Darby canine kidney (MDCK) cells (Simons and Wandinger-Ness, 1990). Although there is a lack of detailed ultrastructural studies of the distribution of internal GEM rafts, the fact that apical and basolateral sorting is believed to take place in the

\footnotetext{
+ These authors contributed equally to this work.

$\S$ Corresponding author. E-mail address: maalonso@cbm.uam.es. Abbreviations used: ER, endoplasmic reticulum; d, dog; GEM, glycolipid- and cholesterol-enriched membrane; h, human; HA, hemagglutinin; MDCK, Madin-Darby canine kidney; mAb, monoclonal antibody; PBS, phosphate-buffered saline; sulfoNHS-biotin, sulfo-N-hydroxyl-succinimido-biotin; TGN, transGolgi-network.
}

trans-Golgi-network (TGN) has led to the assumption that internal GEMs are specialized subdomains of this compartment (Simons and Ikonen, 1997). The role of internal GEM rafts in apical traffic is supported by evidence obtained from the prototypical MDCK cell system, which shows that the influenza virus hemagglutinin (HA) is incorporated into GEMs during biosynthetic transport to the apical surface (Skibbens et al., 1989), and that alteration of GEM integrity by cholesterol sequestration impairs apical transport of HA (Keller and Simons, 1998).

The partition of proteins into GEMs could provide the biophysical basis for inclusion in apical vesicles, however, to function as a route of transport GEMs require specialized protein-sorting machinery. MAL is a nonglycosylated integral membrane protein of $17 \mathrm{kDa}$ containing multiple hydrophobic segments (Alonso and Weissman, 1987) that, in contrast with most integral membrane proteins, is highly soluble in organic solvents used to extract cell lipids. Endogenous MAL (VIP17, MVP17) is localized at steady state 
predominantly in the apical zone of polarized epithelial cells (Martín-Belmonte et al., 1998) and displays the distinctive biochemical feature of selective residence in GEMs in all the cell types in which it is expressed (Kim et al., 1995; Zacchetti et al., 1995; Martín-Belmonte et al., 1998; Millán and Alonso, 1998). The observation that ectopic expression of MAL provokes a massive de novo induction of vesicle formation led to the proposal of MAL as being a component of the machinery for GEM vesiculation (Puertollano et al., 1997). With the use of MDCK and Fischer rat thyroid (FRT) cells whose endogenous MAL was depleted, a role for MAL as an element of the apical sorting apparatus necessary for apical transport of HA (Cheong et al., 1999; Puertollano et al., 1999a) and the overall apical membrane proteins, including proteins excluded from the GEM fraction, has recently been demonstrated (Martín-Belmonte et al., 2000). This highlights MAL as the first integral membrane component of the machinery for apical transport identified so far.

The last five carboxyl-terminal amino acids of MAL have the sequence Arg-Trp-Lys-Ser-Ser (RWKSS). Dilysine-based signals (KKXX, where $X$ represents any amino acid) are involved in the retrieval of type I transmembrane proteins to the endoplasmic reticulum (ER) (Jackson et al., 1993). The lysine residues within this motif can be separated by one amino acid $[\mathrm{K}(\mathrm{X})) \mathrm{KXX}]$ without loss of targeting to the ER. Variants of this sequence with Lys -4 (Jackson et al., 1990) or -5 (Shin et al., 1991) substituted by Arg [R/K(X)XX] have been demonstrated to confer ER distribution to reporter proteins, although at least in the first case, with an diminished efficiency (Jackson et al., 1990). In addition to their role as ER-retrieval signals, dilysine-based motifs with the sequence KKFF have been demonstrated to be functional in protein endocytosis (Itin et al., 1995). The functionality of dilysine-based sorting motifs is impaired by either shortening of the carboxyl-terminal sequence, elongation with additional residues, or substitution of either of the basic residues (Jackson et al., 1990). Previous work indicates that the MAL RWKSS pentapeptide can act as an ER-retrieval signal when transplanted onto the reporter CD4 transmembrane protein and that the substitution of the serines by alanine (MAL-RWKAA) targets MAL to the ER (Puertollano and Alonso, 1999a). This indicates that the RWKSS sequence, although it does not work in the MAL molecule as an ER-targeting signal, is related to dilysine-based motifs involved in ER retrieval.

MAL enhances the presence of HA in GEMs, and the depletion of endogenous MAL reduces transport of HA to the apical surface and produces its partial missorting to the basolateral subdomain in MDCK cells (Puertollano et al., 1999a). Consistent with its role as an element of the sorting machinery, we have recently demonstrated that MAL behaves as an itinerant protein cycling between the cell surface and endosomes and, to a lesser extent, the TGN (Puertollano and Alonso, 1999b). It is plausible that sequences in the MAL molecule might be responsible for the regulation of its trafficking. To try to understand the mechanism by which MAL promotes apical transport, in this study we have investigated the role of the MAL carboxy terminus in both the distribution and function of MAL by expressing in MDCK cells modified MAL proteins with mutations known to inactivate dilysine-based sorting motifs. Similar to MAL bearing an intact carboxy terminus (MAL-RWKSS), MAL pro- teins with the carboxyl-terminal end altered by deletion of the two serines (MAL-RWK), elongation with three serines (MAL-RWKSSSSS), or substitution of lysine -3 by serine (MAL-RWSSS) enhance the presence of HA in GEMs. However, in contrast to MAL-RWKSS, neither of the mutants was able to correct the altered phenotype of HA transport induced by depletion of endogenous MAL. Quantitative immunoelectron microscopy analysis indicated that, compared with MAL-RWKSS, MAL-RWSSS showed a twofold increase in the presence in clathrin-coated cytoplasmic structures and a reduced expression on the plasma membrane. These results indicate that the carboxyl-terminal RWKSS sequence of MAL modulates the distribution of the protein in clathrin-coated endosome structures and that an intact dilysine-like sequence in the MAL molecule is necessary for transport of cargo HA molecules to the apical membrane.

\section{MATERIALS AND METHODS}

\section{Materials}

The mouse monoclonal antibody $(\mathrm{mAb})$ 9E10 against the c-Myc epitope EQKLISEED was obtained from the American Type Culture Collection (Rockville, MD). The rabbit polyclonal antibodies to the c-Myc epitope or to transferrin were purchased from Santa Cruz Biotechnology (Santa Cruz, CA) and Dako A/S (Glostrup, Denmark), respectively. Mouse mAbs to E-cadherin, EEA1 or calnexin, and rabbit polyclonal antibodies to caveolin were obtained from Transduction Labs (Nottingham, United Kingdom). The anti-HA $\mathrm{mAb}$ was a kind gift from Dr. E. Rodriguez-Boulan (Cornell University, Ithaca, NY). The mouse mAb 6D9 that recognizes human (h) MAL, and the rat mAb 2E5 specific to dog (d) MAL have been described previously (Martín-Belmonte et al., 1998, Puertollano et al., 1999a). Peroxidase-conjugated secondary anti-Ig antibodies, sulfoN-hydroxyl-succinimido-biotin (sulfo-NHS-biotin), streptavidincoupled agarose, and peroxidase-coupled streptavidin were supplied by Pierce (Rockford, IL). Triton X-100 and the mouse mAbs to the FLAG epitope and $\gamma$-adaptin were purchased from Sigma Chemical (St. Louis, MO). Protein A-gold conjugates were obtained from the Department of Cell Biology of the Utrecht University (Utrecht, The Netherlands).

\section{Cell Culture and Infection Conditions}

Epithelial MDCK II cells were grown on Petri dishes in Dulbecco's modified Eagle's medium supplemented with $10 \%$ of fetal bovine serum (Life Technologies, Gaithersburg, MD), penicillin $(50 \mathrm{U} / \mathrm{ml})$, and streptomycin $(50 \mu \mathrm{g} / \mathrm{ml})$ at $37^{\circ} \mathrm{C}$ in an atmosphere of $5 \% \mathrm{CO}_{2}$. Influenza virus A/Victoria/3/75 (H3N2) strain (a generous gift from Dr. J. Ortín, Centro Nacional de Biotecnología, Madrid, Spain) was grown and titered on MDCK cells. Confluent cell monolayers were incubated with influenza virus (10 plaque-forming units per cell) for $1 \mathrm{~h}$ at $37^{\circ} \mathrm{C}$ to allow adsorption and entry of the virus. After that (taken as time zero of infection), the inoculum was removed and the cell cultures incubated at $37^{\circ} \mathrm{C}$ for the indicated times in normal medium.

\section{DNA Constructions, Oligonucleotides, and Transfections}

The generation of the DNA constructs expressing c-Myc-tagged hMAL proteins with mutations at the carboxy terminus by either deletion, addition, or substitution of amino acids has been reported previously (Puertollano and Alonso, 1998). The construct expressing a modified MAL molecule harboring a FLAG epitope in its last extracellular loop (MAL/FLAG) has been described previously ( $\mathrm{Pu}-$ ertollano and Alonso, 1999b). A variant of MAL/FLAG in which 
Lys -3 was substituted by Ser (MAL/FLAG-RWSSS) was generated by the polymerase chain reaction with the use of appropriate oligonucleotide primers. Plasmid transfection in MDCK cells was carried out by electroporation. Selection of stable transfectants was carried out by treatment with $0.5 \mathrm{mg} / \mathrm{ml} \mathrm{G}-418$ sulfate for at least $4 \mathrm{wk}$ after transfection. Drug-resistant cell clones were trypsinized in situ with the aid of cloning rings. The clones were screened by immunofluorescence analysis, and those resulting positive for the expression of the indicated protein were maintained in drug-free medium. The 19-mer phosphorothioate oligonucleotides AS, complementary to canine MAL mRNA, and AM, similar in composition to AS but with some replacements to prevent pairing with endogenous canine MAL mRNA, were introduced into MDCK cells by electroporation as described previously (Puertollano et al., 1999a).

\section{Detergent Extraction Procedures}

GEMs were isolated by standard procedures (Brown and Rose, 1992). Cells grown to confluency in $100-\mathrm{mm}$ dishes were rinsed with phosphate-buffered saline (PBS) and lysed for $20 \mathrm{~min}$ in $1 \mathrm{ml}$ of 25 $\mathrm{mM}$ Tris- $\mathrm{HCl}, \mathrm{pH}$ 7.5, $150 \mathrm{mM} \mathrm{NaCl}, 5 \mathrm{mM}$ EDTA, 1\% Triton X-100 at $4^{\circ} \mathrm{C}$. The lysate was scraped from the dishes with a cell lifter, the dishes were rinsed with $1 \mathrm{ml}$ of the same buffer at $4^{\circ} \mathrm{C}$, and the lysate was homogenized by passing the sample through a 22-gauge needle. The extract was finally brought to $40 \%$ sucrose in a final volume of $4 \mathrm{ml}$ and placed at the bottom of an $8 \mathrm{ml} \mathrm{5-30 \%} \mathrm{linear}$ sucrose gradient. Gradients were centrifuged for $18 \mathrm{~h}$ at 39,000 rpm at $4^{\circ} \mathrm{C}$ in a Beckman SW41 rotor. Fractions of $1 \mathrm{ml}$ were harvested from the bottom of the tube and aliquots were subjected to immunoblot analysis. The method of Skibbens et al. (1989) was adopted to analyze the partition of HA into insoluble membranes. Briefly, cell monolayers were extracted for $20 \mathrm{~min}$ on ice with $25 \mathrm{mM}$ Tris- $\mathrm{HCl}$, $\mathrm{pH}$ 7.5, $150 \mathrm{mM} \mathrm{NaCl}, 5 \mathrm{mM}$ EDTA, 1\% Triton X-100 supplemented with a cocktail of proteases. The extracts were then centrifuged in a refrigerated microfuge at $14,000 \mathrm{rpm}$ for $1 \mathrm{~min}$. The supernatant (soluble fraction) was removed, and a small amount of the remaining soluble material was recovered from the pellet (insoluble fraction) after a second centrifugation. The soluble material was pooled, and the pellet resuspended in buffer for SDS-PAGE. Finally, equivalent aliquots from the soluble and insoluble fractions were subjected to SDS-PAGE and analyzed by autoradiography.

\section{Immunoblot Analysis}

Samples were subjected to SDS-PAGE in 15\% acrylamide gels under reducing conditions and transferred to Immobilon-P membranes (Millipore, Bedford, MA). After blocking with 5\% (wt/vol) nonfat dry milk, $0.05 \%$ (vol/vol) Tween 20 in PBS, blots were incubated with the indicated primary antibody. After several washings, blots were incubated for $1 \mathrm{~h}$ with goat anti-mouse (or anti-rat) IgG antibodies coupled to horseradish peroxidase, washed extensively, and developed with the use of an enhanced chemiluminescence Western blotting kit (Amersham Pharmacia Biotech, Arlington Heights, IL). Quantitative analyses were done with a computing densitometer.

\section{Domain-selective Biotinylation}

For separate access to apical or basolateral domains, MDCK cells were seeded at confluent levels on 24-mm polyester tissue culture inserts of $0.4-\mu \mathrm{m}$ pore size (Transwell; Costar, Cambridge, MA). The integrity of the cell monolayer was monitored by measuring the transepithelial electric resistance with the use of the Millicell ERS apparatus (Millipore). For metabolic labeling of cells in filters, cells infected with influenza virus for $2.5 \mathrm{~h}$ were starved in media lacking methionine and cysteine. After $15 \mathrm{~min}, 250 \mu \mathrm{Ci}$ of $\left.{ }^{35} \mathrm{~S}\right]$ methionine/ cysteine was added to the basolateral compartment, and filters were incubated for $2 \mathrm{~h}$ at $37^{\circ} \mathrm{C}$. After repeated washings with ice-cold PBS containing $0.1 \mathrm{mM} \mathrm{CaCl}_{2}$ and $1 \mathrm{mM} \mathrm{MgCl}, 0.5 \mathrm{mg} / \mathrm{ml}$ sulfo-NHS- biotin was added either to the apical or basolateral compartment of the filter chamber. After $30 \mathrm{~min}$ at $4^{\circ} \mathrm{C}$, the solution was removed and remaining unreacted biotin quenched by incubation with icecold serum-free Dulbecco's modified Eagle's medium. Cell monolayers were finally washed with PBS and extracted with $0.5 \mathrm{ml}$ of 25 mM Tris- $\mathrm{HCl}, \mathrm{pH} 7.5,150 \mathrm{mM} \mathrm{NaCl}, 5 \mathrm{mM}$ EDTA, $1 \%$ Triton X-100, $60 \mathrm{mM}$ octyl-glucoside for $30 \mathrm{~min}$ on ice. Extracts were immunoprecipitated with streptavidin-agarose, and the immunoprecipitates fractionated by SDS-PAGE. To detect the presence of ${ }^{35} \mathrm{~S}$-labeled HA on the cell surface, blots were exposed to imaging plates. To detect surface E-cadherin, the streptavidin-agarose immunoprecipitates were analyzed by immunoblot with anti-E-cadherin antibodies.

\section{Confocal Immunofluorescence Analysis}

MDCK cells grown on tissue culture inserts were fixed in $4 \%$ paraformaldehyde for $15 \mathrm{~min}$, rinsed, and treated with $10 \mathrm{mM}$ glycine for $5 \mathrm{~min}$ to quench the aldehyde groups. The cells were then permeabilized with $0.2 \%$ Triton X-100, rinsed, and incubated with $3 \%$ bovine serum albumin in PBS for $15 \mathrm{~min}$. Cells were then incubated for $1 \mathrm{~h}$ with mAb 9E10, rinsed several times, and incubated for $1 \mathrm{~h}$ with anti-mouse IgG coupled to Texas Red. Images were obtained with the use of a Bio-Rad Radiance 2000 Confocal Laser microscope (Hercules, CA). Controls to assess the specificity of the labeling included incubations with control primary antibodies or omission of the primary antibodies.

\section{Quantitative Immunoelectron Microscopy}

Stable transfectants of epithelial MDCK cells expressing tagged hMAL proteins were used. The cells were processed for cryosectioning as described (Martínez-Menárguez et al., 1999). Briefly, the cells were fixed overnight with $4 \%$ paraformaldehyde in $0.1 \mathrm{M}$ phosphate buffer, pelleted by centrifugation, embedded in $10 \%$ gelatin, and cut into small blocks. The blocks were infused with 2.3 $\mathrm{M}$ sucrose, frozen in liquid nitrogen, and stored until cryo-ultramicrotomy. Cryosections were single immunolabeled with rabbit polyclonal antibodies or mouse $\mathrm{mAb}$ followed by protein A-gold. In the latter case, a bridging rabbit anti-mouse IgG antibody was applied. Double immunolabeling was carried out as described by Slot $e t$ al. (1991). The distribution of MAL-RWKSS and MAL-RWSSS in MDCK cells was determined with anti-tag mAb 9E10. Selected areas of the grids that contained cells exhibiting normal morphology were scanned along a fixed track. Gold particles (1500 in 3 independent sessions of 500 gold particles for each protein) were counted and ascribed to one of the after categories: Golgi area (including Golgi stack of cisterna and associated vesicles and tubules), cytoplasmic uncoated vesicles and tubules, cytoplasmic clathrin-coated vesicles and tubules, multivesicular bodies, and plasma membrane (including coated pits and buds). The number of gold particles found for each category was expressed as a percentage of the total particles counted. The presence of a clathrin coat was established on the basis of the typical thickness and appearance of the coats in cryosections (Martínez-Menárguez et al., 1999). To establish the percentage of MAL-reactive cytoplasmic vesicles and tubules that contained detectable caveolin-1, EEA1, or transferrin label, 100 MAL-reactive vesicles/tubules were screened for the presence or absence of label for the protein under study. The same procedure was used for $\gamma$-adaptin but only MAL-reactive cytoplasmic vesicles/tubules showing a characteristic clathrin-coat $(n=50)$ were considered. For double-labeling of HA and MAL, MDCK cells stably expressing tagged hMAL were infected with influenza virus A WSN strain (a kind gift from Dr. E. Rodriguez-Boulan) for $4 \mathrm{~h}$. Cryosections were double immunolabeled with anti-tag rabbit polyclonal antibodies and anti-HA mAb. For quantification, $100 \mathrm{MAL}-$ reactive vesicles/ tubules were screened for the presence of label for HA. 
A FRACTION NUMBER Bottom

123456789101112

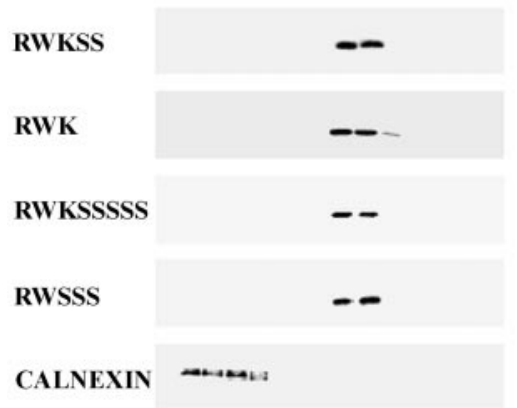

B

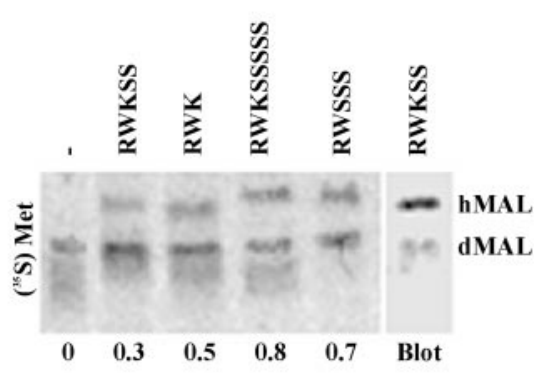

Figure 1. Mutations in the MAL carboxyl-terminal RWKSS sequence known to impair the functionality of dilysine-based signals do not affect the incorporation of MAL into GEMs in MDCK cells. (A) MDCK cells expressing taggedMAL with an intact carboxy terminus (MALRWKSS), or mutants of this protein in which 1) the carboxyl-terminal serines were deleted (MAL-RWK); 2) the carboxy terminus was elongated with three serines (MAL-RWKSSSSS); or 3) lysine -3 was substituted by serine (MALRWSSS) were extracted with $1 \%$ Triton X-100 at $4^{\circ} \mathrm{C}$ and centrifuged to equilibrium in sucrose density gradients after standard procedures. After fractionation from the bottom of the tube, aliquots from the different fractions were subjected to immunoblot analysis with anti-tag $\mathrm{mAb}$ 9E10. Fractions 1-4 are the $40 \%$ sucrose layer and contain the bulk of cellular membranes and cytosolic proteins, whereas fractions 5-12 are the $5-30 \%$ sucrose layer and contain GEMs. The distribution of calnexin, an ER transmembrane protein that is excluded from GEMs, was used as a control for the fractionation procedure. (B) Comparative analysis of the levels of expression of exogenous and endogenous MAL in the different MDCK cell transfectants. Normal MDCK cells or MDCK cells stably expressing either MAL-RWKSS, MAL-RWK, MAL-RWKSSSSS, or MAL-RWSSS were labeled with $\left[{ }^{35} \mathrm{~S}\right]$ methionine/cysteine for $16 \mathrm{~h}$ and were then extracted with $1 \%$ Triton X-100 at $4{ }^{\circ} \mathrm{C}$. The GEM fraction was collected and solubilized with $60 \mathrm{mM}$ octyl-glucoside to solubilize GEMs. The solubilized material was then extracted with $n$-butanol, and the organic phase containing proteolipids was dried and analyzed by SDS-PAGE. Two major proteolipid bands were observed by autoradiography. Additional minor bands were detected with longer exposures (our unpublished results). The major bands were identified as endogenous dMAL and exogenous hMAL by immunoblot analysis with antibodies 2E5 and 9E10, respectively, of the sample obtained from cells expressing MAL-RWKSS. Numbers at the bottom of the autoradiogram indicate the level of expression of the different exogenous hMAL proteins relative to that of endogenous dMAL. These values were calculated by quantification of the radiolabeled hMAL and dMAL bands obtained in the different transfectants, taking into account the content in methionine and cysteine residues in hMAL and dMAL.

\section{RESULTS}

\section{Stable Expression in MDCK Cells of MAL Proteins Harboring Mutations in the Carboxyl-Terminal RWKSS Sequence}

The MAL sequence corresponding to carboxyl-terminal amino acids from -5 to -1 (RWKSS) resembles the dilysinebased sorting signals $[\mathrm{K} / \mathrm{R}(\mathrm{X}) \mathrm{KXX}]$ present in the carboxy terminus of certain proteins (Jackson et al., 1990; Shin et al., 1991; Itin et al., 1995). Partially coinciding with this motif, our previous mutational analysis in A498 cells led to the identification of the Leu-Ile-Arg-Trp (LIRW) tetrapeptide spanning from -7 to -4 , which is required for MAL sorting to GEMs (Puertollano and Alonso, 1998). The LIRW motif requires at least one additional amino acid at its $\mathrm{COOH}$ terminus to be fully effective. The arginine within the LIRW motif is the most crucial residue and does not tolerate even substitution by lysine. Tryptophan replacement by either phenylalanine, serine, or leucine also affects targeting although to a lesser extent than with arginine replacement (Puertollano and Alonso, 1998). Keeping in mind these constraints, we have focused on the study of the distribution and function of mutants in the carboxyl-terminal RWKSS sequence of MAL, maintaining intact the arginine and tryptophan residues to allow the complete incorporation of the modified MAL proteins into GEMs. Because our previous mutational study was done in epithelial A498 cells, which lack endogenous expression of MAL (Puertollano and Alonso, 1998), we first analyzed whether the mutants were also able to access to GEMs in MDCK cells, which express MAL endogenously. To study the MAL mutants at steady state, the analysis was carried out with the use of MDCK cells that stably express hMAL proteins tagged at their amino terminus with the 9E10 c-Myc epitope. It has been previously demonstrated that the presence of this tag does not interfere with either the targeting of the wild-type MAL protein to GEMs (Millán et al., 1997) or its function in apical transport in MDCK cells (Puertollano et al., 1999a). Figure 1A shows that neither deletion of the last two serine residues (MAL-RWK), elongation of the carboxyl-terminal end with three serines (MAL-RWKSSSSS) nor substitution of lysine -3 by serine (MAL-RWSSS), mutations that neutralize typical dilysine-based motifs, interfere with the capacity of MAL to become incorporated into GEMs in MDCK cells. Because there are no anti-MAL antibodies available that simultaneously recognize the dog and human species, to estimate the level of expression of the exogenous proteins relative to that of endogenous MAL in the transfected MDCK cells, we labeled the cells with [ ${ }^{35}$ S]methionine/ cysteine and, after extraction of the proteolipids present in GEMs, we quantified the intensity of the signals corresponding to the exogenous (hMAL) and endogenous (dMAL) MAL proteins. This analysis demonstrated that exogenous expression of hMAL ranged from 0.3- to 0.8-fold that of endogenous MAL in the different transfectants (Figure 1B). This excludes the possibility that massive overexpression might affect the distribution and/or the function of the exogenous MAL molecules in our MDCK cell transfectants.

\section{Subcellular Distribution of MAL-RWKSS}

To determine the distribution of MAL-RWKSS in MDCK cells and for subsequent comparison with that of MALRWSSS, we used immunoelectron microscopy on ultrathin 
Figure 2. Immunoelectron microscopy analysis of the distribution of MAL-RWKSS in MDCK cells. Ultrathin cryosections of MDCK cells expressing MAL-RWKSS were immunolabeled for MAL with the use of anti-tag antibodies followed by 10-nm protein-A gold. (a) Overall distribution of MAL proteolipid. Specific labeling is associated with small tubular/vesicular structures (arrows) as well as plasma membrane (arrowhead). (b) Detail of MAL-immunoreactive intracellular elements. Note that the labeling is restricted to the membrane of these elements. Arrow points to an immunolabeled clathrincoated vesicular profile. On the left a short tubule is highly labeled (arrowhead). (c) Both clathrin-coated buds (arrow) and vesicular profiles (arrowhead) show reactivity. (d) Detail of a Golgi area where tubular (arrow) and vesicular profiles (arrowhead) are reactive. (e) Multivesicular bodies (stars) were usually not immunoreactive. This micrograph shows an unusual case of multivesicular bodies labeled for MAL. Note that the labeling is at the inner vesicles (arrows). Pm, plasma membrane; G, Golgi stack. Bars, $200 \mathrm{~nm}$.

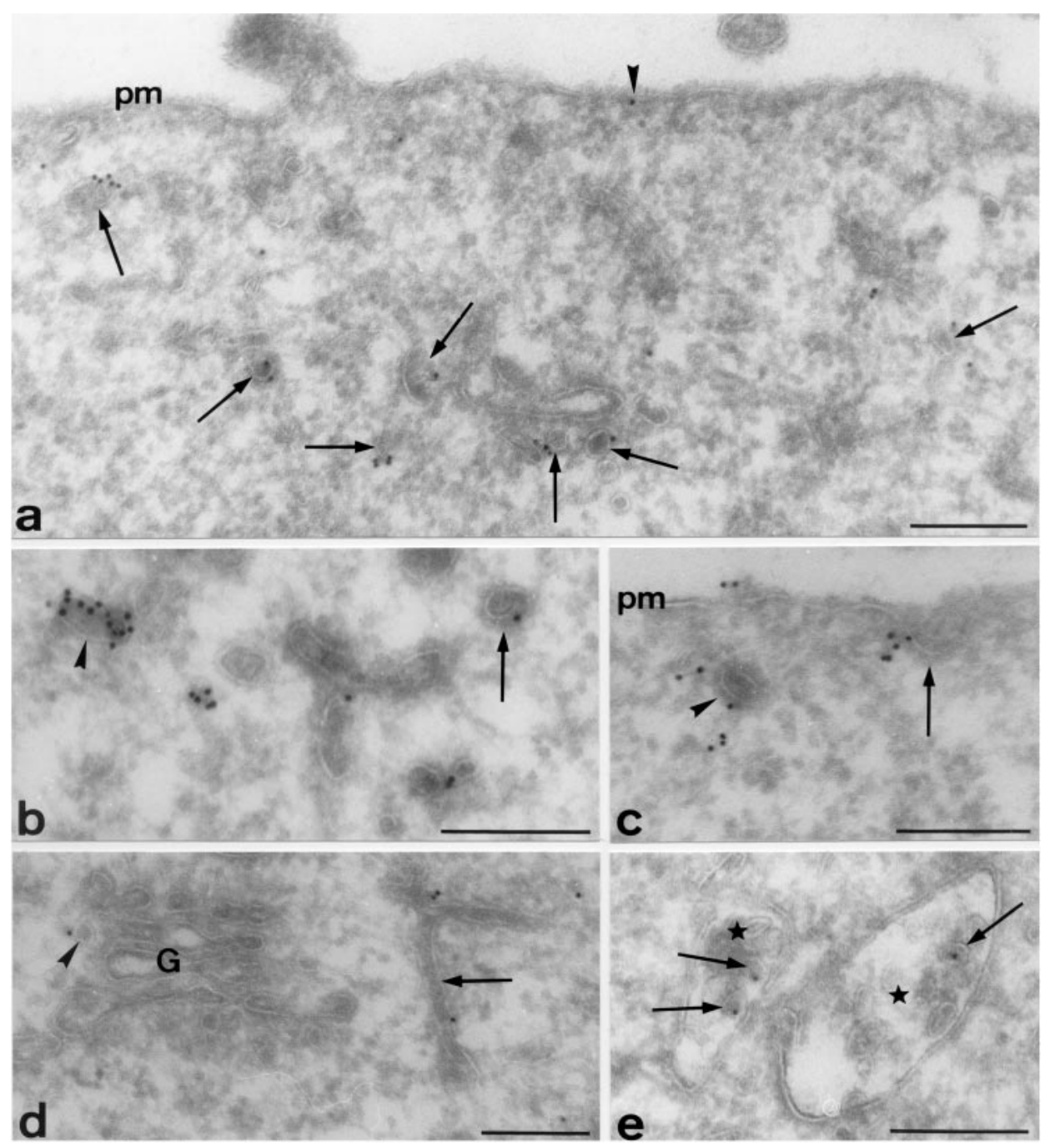

cryosections. Because the level of expression of MALRWKSS was lower than that of the endogenous dMAL protein, the distribution of MAL-RWKSS probably approximates to that of the endogenous protein. This distribution has not been established so far because our current anti$\mathrm{dMAL} \mathrm{mAb}$ is not of use for immunoelectron microscopy studies. As a control for the specificity of the antibodies used, the distribution of MAL-RWKSS was investigated with the use of three different antibodies: anti-tag mAb 9E10, a rabbit polyclonal antibody to the same tag, and anti-hMAL $\mathrm{mAb}$ 6D9. Similar results were obtained with the different antibodies used (our unpublished results). Figure 2 shows that MAL labeling was localized in both the plasma membrane and intracellular structures. Most of the intracellular labeling was on tubular/vesicular profiles situated close to the plasma membrane (Figure 2, a-c) as well as in the proximity of the Golgi stacks (Figure 2d). In addition, plasma membrane clathrin-coated pits and buds were also labeled (Figure 2c) as identified on the basis of the typical thickness and appearance of the clathrin coats in cryosections (Martínez-Menárguez et al., 1999). Specific labeling was also observed in Golgi-associated vesicular profiles (Figure 2d) and occasionally in the Golgi stack (our unpublished results). Labeling of multivesicular bodies was only detected occasionally (Figure 2e). No labeling was observed in lysosomes (Figure 3, a and e). In general, the tubules appeared on ultrathin section as short and nonbranching structures of 50-70 nm in thickness (Figure 2, a and b), although long reactive tubules were also observed (Figures $2 \mathrm{~d}$ and $3 \mathrm{~d}$ ). A fraction of the tubular/vesicular profiles was covered by a characteristic 18-nm-thick clathrin coat (Figure 2, a-c). Quantitative analysis (Table 1, A) indicated that most of the labeling for MAL is associated with noncoated cytoplasmic tubular/vesicular structures $(81.9 \pm 0.9 \%$ of the total labeling in the cell). A significant fraction of these profiles had a clathrin coat ( $4.4 \pm 0.1 \%$ of the total labeling). In addition, a high percentage of MAL immunoreactivity was located at the plasma membrane, including clathrin-coated pits and buds $(11.7 \pm 2.4 \%$ of the total labeling). The labeling at the Golgi area and multivesicular bodies was very low $(0.6 \pm 0.1$ and $1.4 \pm 0.6 \%$, respectively, of the total labeling). 

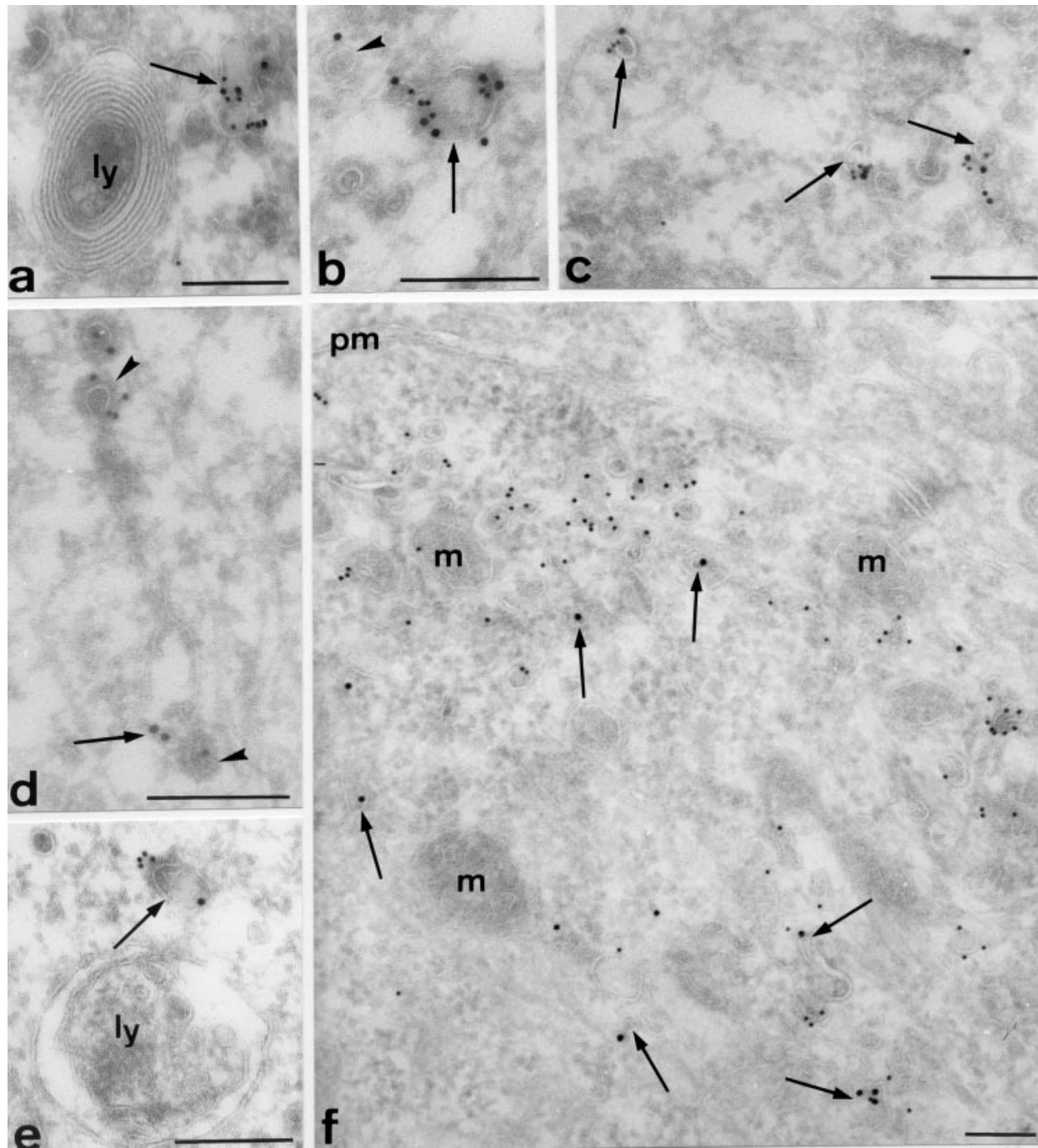

Figure 3. Colocalization studies of MAL-RWKSS with endocytosed transferrin, $\gamma$-adaptin, and caveolin-1 in MDCK cells by immunoelectron microscopy. Ultrathin cryosections of MDCK cells expressing MALRWKSS were double immunolabeled for MAL with the use of anti-tag antibodies and 15-nm protein-A gold particles and for transferrin $(\mathrm{a}-\mathrm{c})$, $\gamma$-adaptin (d and e), or caveolin-1 (f) with the appropriate antibodies and 10-nm protein-A gold particles. (a-c) MAL and transferrin colocalize in membrane elements of different morphology (arrows) such as short tubular profiles (a), vacuolar elements (b), and small vesicular profiles (c). Arrowhead in b points to a MAL-immunoreactive vesicular element that does not contain endocytosed transferrin. (d and e) Examples of MALimmunoreactive tubules showing a characteristic clathrin coat containing $\gamma$-adaptin. Arrows and arrowheads point to MAL and $\alpha$-adaptin labeling, respectively. (f) Despite the high labeling observed for caveolin-1, most MAL-immunoreactive elements (arrows) do not contain this protein. Ly, lysosome; $\mathrm{m}$, mitochondria; $\mathrm{pm}$, plasma membrane. Bars, $200 \mathrm{~nm}$.
Double-labeling experiments were performed to characterize further the cytoplasmic structures that contained MAL (Figure 3 and Table 1B). Some of the labeled tubular structures display a complex morphology resembling that of recycling endosomes (Gruenberg and Maxfield, 1995). To confirm this association, cells were incubated with transferrin for $30 \mathrm{~min}$, washed, incubated for an additional 10 min, and processed for immunoelectron microscopy. Under the conditions used, transferrin accumulates mostly in recycling endosomes, and allows the labeling of these structures with anti-transferrin antibodies (Yamashiro et al., 1984). Figure $3, a-c$, shows that a high percentage $(49 \pm 3 \%)$ of the cytoplasmic tubular/vesicular profiles containing MALRWKSS were also positive for endocytosed transferrin. As mentioned, a small percentage of the membranes with MALRWKSS showed a characteristic clathrin coat. So far, four different adaptor complexes have been described (Le Borgne and Hoflack, 1998; Dell'Angelica et al., 1999; Hirst et al., 1999). $\gamma$-Adaptin, a component of the AP-1 adaptor complex, has been detected at both the TGN and recycling endosomes (Robinson, 1990; Futter et al., 1998). With the use of a mAb to $\gamma$-adaptin we estimate that $\sim 38 \pm 10 \%$ of the population of clathrin-coated membranes positive for MAL-RWKSS were also reactive for $\gamma$-adaptin (Figure 3, $\mathrm{d}$ and e). To investigate in detail the relationship between MAL and other components of the protein machinery acting in GEMs, we compare the distribution of MAL-RWKSS with that of caveolin-1 (Figure 3f), a component of GEM microdomains involved in the biogenesis of caveolae (Anderson, 1998; Smart et al., 1999). Quantitative analysis showed that $\sim 9 \pm 4 \%$ of MALRWKSS colocalized with caveolin-1 in the same intracellular structures (Figure $3 \mathrm{f}$ ). This caveolin represents $\sim 1 \%$ of the total caveolin-1 labeling. This observation is consistent with previous findings showing the presence of caveolin-1 in intracellular structures (Dupree et al., 1993), and with reports supporting that MAL and caveolin-1 mostly segregated into different GEM microdomains (Millán et al., 1997) and have different lipid requirements for efficient integration into artificial lipid bilayers (Puertollano et al., 1999b). Finally, we carried out colocalization studies between EEA1, a protein predominantly found in sorting endosomes (Wilson et al., 2000), and MAL. The immunoelectron microscopic analysis 
Table 1. Quantitative analysis of the subcellular distribution of MAL-RWKSS and MAL-RWSSS in MDCK cells

\begin{tabular}{lcc} 
A & & \\
\hline & $\begin{array}{c}\text { MAL- } \\
\text { RWKSS }\end{array}$ & $\begin{array}{c}\text { MAL- } \\
\text { RWSSS }\end{array}$ \\
\hline Coated cytoplasmic vesicles/tubules & $4.4 \pm 0.1^{\mathrm{a}}$ & $9.0 \pm 1.4^{\mathrm{a}}$ \\
Uncoated cytoplasmic vesicles/tubules & $81.9 \pm 0.9$ & $82.5 \pm 0.8$ \\
Multivesicular bodies & $1.4 \pm 0.6$ & $0.5 \pm 0.2$ \\
Golgi stacks & $0.6 \pm 0.1$ & $0.3 \pm 0.2$ \\
$\begin{array}{l}\text { Plasma membrane, including coated } \\
\text { pits and buds }\end{array}$ & $11.7 \pm 2.4^{\mathrm{b}}$ & $7.7 \pm 1.1^{\mathrm{b}}$ \\
\hline
\end{tabular}

B

Transferrin $\gamma$-adaptin ${ }^{c}$ Caveolin-1 EEA1 HA

MAL-RWKSS $\quad 49 \pm 3 \% \quad 38 \pm 10 \% \quad 9 \pm 4 \% \quad 8 \pm 1 \% 36 \pm 7 \%$

Numbers represent the percentages (mean \pm SEM) of the total labeling over the distinct compartments (A) or the colocalization of the indicated molecules with MAL-reactive tubular/vesicular structures (B).

$\mathrm{a}, \mathrm{b}$ Statistically significant differences ( $\mathrm{p} \leq 0.05$ ).

${ }^{c}$ Only MAL-reactive structures coated with clathrin were analyzed.

(our unpublished results) indicated that $8 \pm 1 \%$ of the tubular/vesicular structures reactive for MAL were also positive for the EEA1 marker (Table 1 B). In summary, our data suggest that MAL-RWKSS is predominantly detected in tubular/vesicular elements with a morphology resembling that of early endosomes. A high percentage of these elements was also positive for endocytosed transferrin and $\gamma$-adaptin, suggesting that they correspond to recycling endosomes, whereas a small percentage might correspond to sorting endosomes, as suggested by colocalization with the EEA1 marker. A small percentage of the elements immunoreactive for MAL-RWKSS displays a characteristic clathrin coat. In some cases, colocalization of MAL-RWKSS and caveolin-1 was noted in the same structures, in agreement with the recent reported presence of caveolin-1 in recycling endosomes (Gagescu et al., 2000).

\section{HA Colocalizes with MAL in Internal Tubular/Vesicular Structures in MDCK Cells}

We and others have previously shown that MAL is required for normal transport of HA to the apical surface in polarized epithelial cells (Cheong et al., 1999; Puertollano et al., 1999a; Martín-Belmonte et al., 2000). The predominant presence of MAL in internal tubular/vesicular elements led us to examine whether newly synthesized HA en route to the plasma membrane colocalizes with MAL. MDCK cells stably expressing MAL-RWKSS were infected with influenza virus and, after $4 \mathrm{~h}$ of infection, cells were fixed and processed for detection of MAL and/or HA with the use of immunoelectron microscopy. Figure 4a shows that HA was distributed at the cell surface and in internal tubular/vesicular elements distributed throughout the cell. The Golgi apparatus was also strongly labeled (our unpublished results). With the use of double-labeling experiments we estimate that $\sim 36 \pm 7 \%$ of the population of the internal tubular/vesicular structures positive for MAL-RWKSS were also reactive for HA (Figure 4, b-d, and Table 1B). In addition to these structures, HA was also found in membrane elements that were unreactive for MAL (Figure 4b). Occasionally, influenza viral particles budding from the plasma membrane were found to be positive for MAL (Figure $4 \mathrm{a}$, inset).

\section{Normal HA Insolubility Does Not Require an Intact RWKSS Sequence in the MAL Molecule}

Consistent with the proposed role of MAL in raft organization (Puertollano et al., 1997), we have previously observed that depletion of endogenous MAL diminished the presence of HA in GEMs, as measured by insolubility in 1\% Triton $\mathrm{X}-100$ at $4^{\circ} \mathrm{C}$ (Puertollano et al., 1999a). To investigate whether MAL requires an intact carboxy terminus to stabilize HA in GEMs we compared the insolubility of HA with the use of MDCK cells with reduced levels of endogenous MAL stably expressing either MAL-RWKSS or the indicated MAL carboxyl-terminal mutants. To this end, cells were transfected with oligonucleotides AM or AS, and infected $48 \mathrm{~h}$ later with influenza virus. After $2.5 \mathrm{~h}$, cells were labeled with [ ${ }^{35} \mathrm{~S}$ ]methionine/cysteine for $10 \mathrm{~min}$, and chased for $2 \mathrm{~h}$ in normal medium. The soluble and insoluble fractions were separated by centrifugation in a microfuge after extraction of the cells with $1 \%$ Triton X-100 at $4^{\circ} \mathrm{C}$ after the procedure of Skibbens et al. (1989) and were subjected to SDS-PAGE and autoradiographed. HA was easily identified due to the profound shutoff of host protein synthesis induced by influenza virus infection. The extent of endogenous dMAL depletion was quantified by densitometric analysis of immunoblots with anti-dMAL mAb 2E5 of the lysates obtained from cells transfected with either oligonucleotide AM or AS, and the partition of radiolabeled HA into the soluble and insoluble fractions was measured by densitometric analysis of the autoradiograms. Figure 5 shows that whereas, consistent with our previous reports (Puertollano et al., 1999a), HA insolubility decreased with the reduction of endogenous MAL levels, the ectopic expression of either MAL-RWKSS, MAL-RWK, MAL-RWKSSSSS, or MAL-RWSSS in these cells rescues the insolubility of $\mathrm{HA}$ at levels similar to that of normal cells.

\section{Carboxyl-Terminal RWKSS Sequence of MAL Is Required for Normal Apical Transport and Accurate Sorting of $\mathrm{HA}$}

We have previously observed that the ectopic expression on MAL-RWKSS in MDCK cells was able to restore normal levels of apical transport of HA and correct the missorting of this molecule observed in cells whose endogenous MAL protein is depleted (Puertollano et al., 1999a). To investigate the possible role of the dilysine-like RWKSS sequence of the carboxy terminus of MAL, we analyzed the effect on HA transport of the expression of MAL-RWK, MAL-RWSSS, and MAL-RWKSSSSS proteins in MDCK cells with depleted levels of endogenous MAL. To this end, cells were transfected with either oligonucleotides AM or AS, and seeded at high density $\left(3.5-5.0 \times 10^{5}\right.$ cells $\left./ \mathrm{cm}^{2}\right)$ on filter culture inserts. After $48 \mathrm{~h}$ at $37^{\circ} \mathrm{C}$, the integrity of the cell monolayers was checked, and intact cell monolayers were infected with 


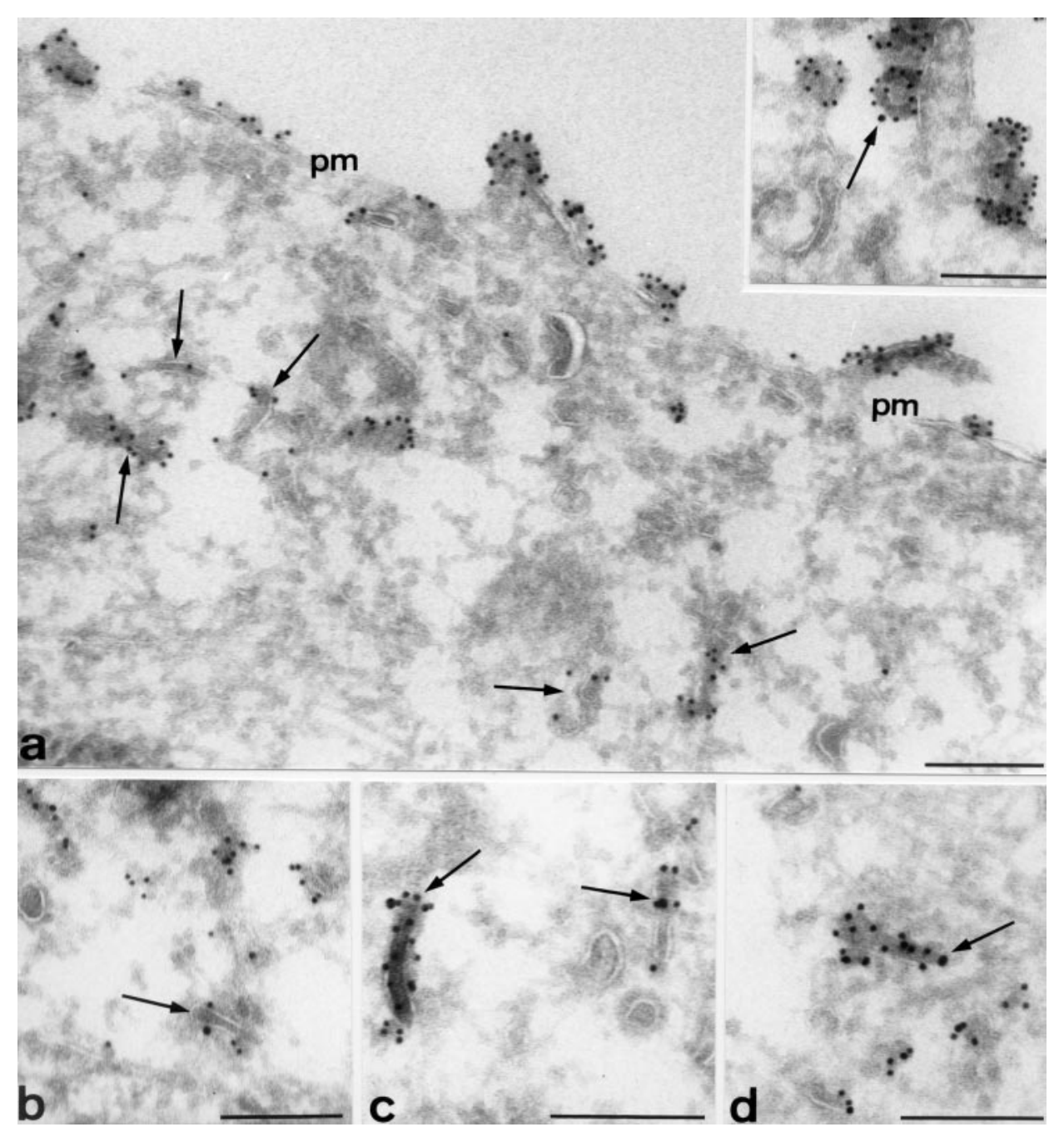

Figure 4. Colocalization studies of MAL with HA in MDCK cells by immunoelectron microscopy. Ultrathin cryosections of MDCK cells stably expressing tagged MAL-RWKSS were infected with influenza virus for $4 \mathrm{~h}$ and processed for either single immunolabeling for HA with the use of anti-HA antibodies followed by 10-nm protein-A gold (a) or double immunolabeling for MAL, with the use of anti-tag rabbit polyclonal antibodies plus $15-\mathrm{nm}$ protein-A gold, and $\mathrm{HA}$, with anti-HA mAb plus 10-nm protein-A gold (inset in a and b-d). (a) HA is detected at the plasma membrane (pm) as well as in intracellular membranes (arrows). Many of these structures display a tubular/vesicular appearance. (inset) Detail of viral particles budding from the plasma membrane. Occasionally, these particles also contain MAL (arrow). (b-d) These pictures show examples of tubular/vesicular membranes reactive for both MAL and HA (arrows). Nonreactive membranes and elements only reactive for HA can be also seen. Bars, $200 \mathrm{~nm}$. influenza virus. Then, $2.5 \mathrm{~h}$ after removal of the inoculum, newly synthesized proteins were labeled with [ $\left.{ }^{35} \mathrm{~S}\right]$ methionine/cysteine for $2 \mathrm{~h}$. Surface proteins were then separately biotinylated from the apical or basolateral surface and immunoprecipitated with streptavidin-agarose. The apical or basolateral surface expression of HA was determined by autoradiography of the corresponding streptavidin-agarose immunoprecitate. As an internal control, the sorting of Ecadherin, a basolateral protein (Le Bivic et al., 1990), was determined by immunoblot analysis with anti-E-cadherin antibodies of the streptavidin-agarose immunoprecipitates. The extent of MAL depletion obtained in each experiment was quantified by densitometric scanning of immunoblots of the initial lysates with anti-dMAL 2E5 mAb. Figure 6A shows that a drop in endogenous MAL in normal MDCK cells to $\sim 10 \%$ of the normal levels reduced apical transport of HA to $35 \%$ of that in control cells and produced an increased missorting of $\mathrm{HA}$ to the basolateral membrane. Consistent with our previous findings (Puertollano et al., 1999a), the expression of exogenous MAL-RWKSS restored normal apical delivery of HA and prevented missorting to the basolateral membrane, in spite of the drop in endoge- nous MAL produced by the antisense AS oligonucleotide. It is of note that the effect of MAL-RWKSS in rescuing the normal phenotype of MDCK cells on HA transport was not achieved by expression of any of the MAL carboxyl-terminal mutants (Figure 6A). A quantitative analysis of the results obtained concerning HA transport with the different MDCK cell transfectants is shown in Figure 6B. Overall, the results in Figures 4 and 5 indicate that the mutations assayed, which are known to neutralize standard dilysine-based sorting motifs, produce MAL molecules that are unable to direct normal HA transport to the cell surface although they retain the capacity to increase the insolubility of HA.

\section{Subcellular Distribution of MAL-RWSSS}

To investigate the effect of the mutations introduced into the RWKSS pentapeptide on the distribution of MAL, we analyzed by confocal microscopy the localization of the different MAL mutants with the use of polarized MDCK cells grown on filters. Figure 7A show three optical $x-y$ sections from the apical surface to the base of the cell layer and Figure 7B shows the $x-z$ section of MDCK cells expressing MAL- 


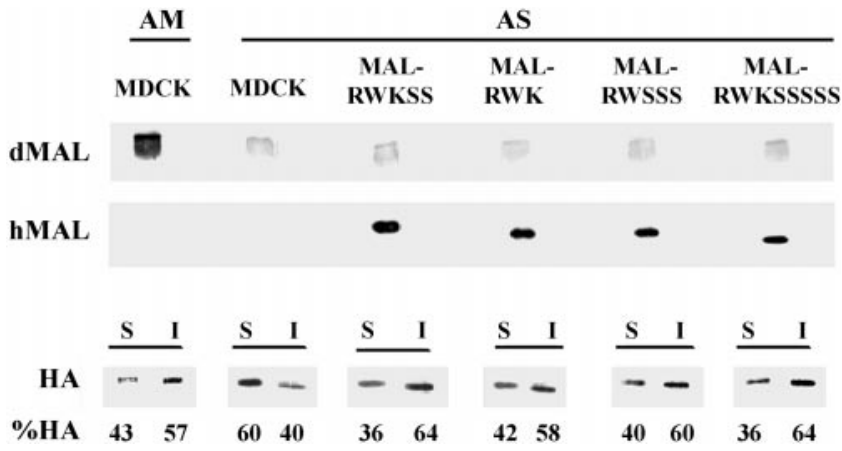

Figure 5. Effect of MAL-RWK, MAL-RWSSS, and MALRWKSSSSS on the insolubility of HA in MDCK cells whose endogenous MAL protein was depleted. Normal MDCK cells or MDCK cells stably expressing either MAL-RWKSS, MAL-RWK, MALRWSSS, or MAL-RWKSSSSS were transfected with either oligonucleotide AM or AS, and incubated at $37^{\circ} \mathrm{C}$. The amount of endogenous dMAL in these cells was analyzed by immunoblotting with $2 \mathrm{E} 5 \mathrm{mAb}$ at $48 \mathrm{~h}$ posttransfection to estimate the extent of MAL depletion. Simultaneously, cells were infected with influenza virus, incubated for $2.5 \mathrm{~h}$, and pulse-labeled with $\left[{ }^{35} \mathrm{~S}\right]$ methionine/cysteine for $10 \mathrm{~min}$. After a 2-h chase, cells were extracted with $1 \%$ Triton X-100 at $4{ }^{\circ} \mathrm{C}$, and the soluble (S) and insoluble (I) fractions separated by centrifugation. Finally, equivalent aliquots from these fractions were subjected to SDS-PAGE and autoradiographed. A representative experiment in which endogenous dMAL levels were decreased to $\sim 15 \%$ of those in normal cells is presented. The HA signals present in the soluble and the insoluble fractions were quantified, as were the values we used to obtain the percentage of radiolabeled HA in the soluble and insoluble fraction in each case. The values obtained in three independent experiments did not vary $>5 \%$ from those shown.

RWKSS. This analysis suggests that, although there was some basolateral staining, MAL-RWKSS was predominantly confined to the apical zone, consistent with the distribution of endogenous MAL observed in thyroid follicles (MartínBelmonte et al., 1998). The $\mathrm{x}-\mathrm{z}$ sections shown in Figure 7B indicate that the modifications introduced into MAL-RWK, MAL-RWSSS, and MAL-RWKSSSSS did not greatly affect the overall distribution of the protein. To investigate in greater detail the effect of neutralizing the putative RWKSS dilysine-based motif, we chose MAL-RWSSS for further comparative analyses with the wild-type MAL-RWKSS molecule.

We have previously reported that MAL recycles, probably after cargo delivery, from the plasma membrane (Puertollano and Alonso, 1999b). To follow the movement of MAL from the plasma membrane, we previously engineered the last extracellular loop of MAL with a FLAG epitope (MAL/ FLAG). This modification does not affect the localization of MAL or its incorporation into GEMs (Puertollano and Alonso, 1999). To investigate whether the substitution of Lys -3 by Ser, which makes MAL defective in apical transport of HA (Figure 6), affects MAL endocytosis we carried out a comparative analysis of the internalization of MAL/FLAG molecules bearing either an intact RWKSS (MAL/FLAGRWKSS) or a mutated RWSSS (MAL/FLAG-RWSSS) sequence with the use of MDCK cells stably expressing either of these proteins. Intact cells were incubated with anti-FLAG antibodies at $4^{\circ} \mathrm{C}$, washed extensively to remove the un- bound $\mathrm{mAb}$, and, after incubation at $37^{\circ} \mathrm{C}$ for different times, MAL internalization was monitored by tracing the antiFLAG mAb bound to the MAL/FLAG molecules originally on the cell surface. Figure $7 C$ shows there is not any apparent difference in the endocytosis rate of the two MAL proteins, ruling out the possibility that the lack of function of MAL-RWSSS in HA transport was due to a defect in the internalization of this molecule from the plasma membrane. To analyze further whether the substitution of Lys-3 by Ser causes any effect on the distribution of MAL, we analyzed the distribution of MAL-RWSSS by immunoelectron microscopic analysis. Figure 8 shows that the MAL-RWSSS protein displays a general profile of distribution similar to that of MAL-RWKSS, being mostly localized to intracellular tubular/vesicular elements and to the plasma membrane. However, a detailed quantitative analysis (Table 1A) revealed that the percentage of MAL-RWSSS in clathrincoated intracellular structures was double that of MALRWKSS and, concomitantly, the percentage of MAL-RWSSS at the plasma membrane was approximately half of that found for MAL-RWKSS. Overall, these data indicate that the single substitution of lysine -3 by serine in the MAL carboxyl-terminal RWKSS pentapeptide modifies the levels of the protein in clathrin-coated cytoplasmic membranes without altering its overall distribution.

\section{DISCUSSION}

\section{MAL-RWKSS Is Predominantly Distributed in Tubulovesicular Endosome Elements in MDCK Cells}

In MDCK cells there are biosynthetic routes that deliver membrane proteins to the apical and basolateral surfaces directly. The TGN has generally been postulated to be the primary site at which polarized sorting takes place (Simons and Wandinger-Ness, 1990; Traub and Kornfeld, 1997). One of the current models of apical transport proposes that partition of membrane proteins into GEM microdomains provides the biophysical basis for the selective recruitment of apically destined proteins (Simons and Wandinger-Ness, 1990; Simons and Ikonen, 1997). These microdomains would act as platforms for the formation of vesicular containers destined for the apical surface with the participation of specific protein machinery. Although the existence of GEM microdomains in the cell surface has been established by different techniques (Friedrichson and Kurzchalia, 1998; Varma and Mayor, 1998), ultrastructural studies of the precise intracellular localization of these specialized membranes are still lacking. Previous work has demonstrated a role for MAL as a component of the integral membrane protein machinery necessary for apical transport of the overall membrane proteins regardless of whether they are detected in the GEM fraction (Cheong et al., 1999; Puertollano et al., 1999a; Martín-Belmonte et al., 2000). The fact that MAL-RWKSS was not overexpressed relative to the endogenous protein in our MDCK cell transfectants allowed us to study the distribution of MAL-RWKSS as an approach to establishing the localization of MAL in MDCK cells. Quantitative immunoelectron microscopy analysis revealed that $81.9 \pm 0.9 \%$ of MAL-RWKSS is present in $50-70-\mathrm{nm}$ tubular/vesicular elements that have a morphology resembling that of early endosomes. Approximately $50 \%$ of the endosome structures containing MAL-RWKSS were also positive 


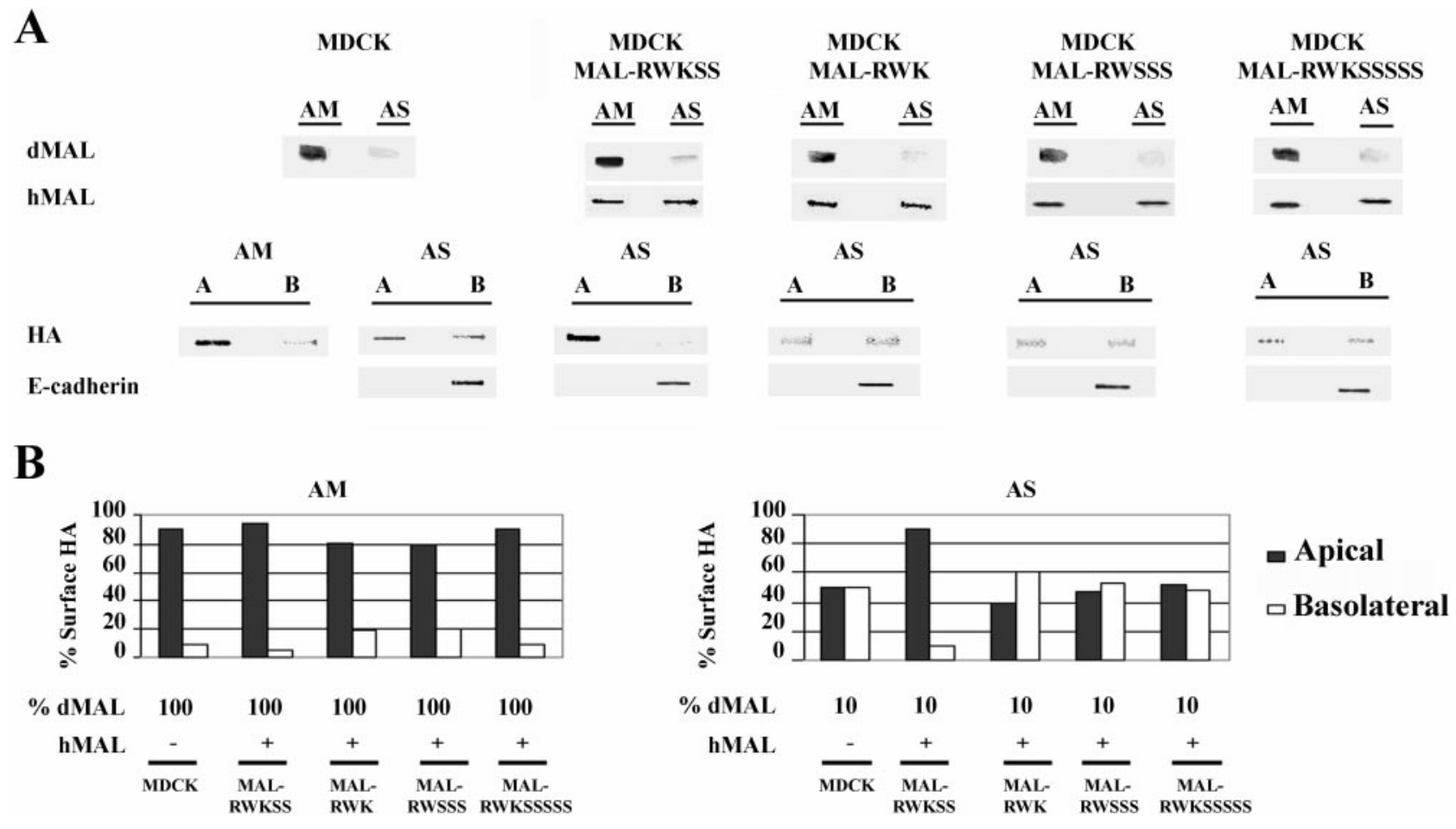

Figure 6. MAL-RWKSS but not MAL-RWK, MAL-RWSSS, or MAL-RWKSSSSS was able to replace endogenous dMAL in directing normal surface transport of HA. (A) Normal MDCK cells or MDCK cells stably expressing either MAL-RWKSS, MAL-RWK, MAL-RWSSS, or MAL-RWKSSSSS were transfected with either oligonucleotide AM or AS, and plated on 24-mm-diameter tissue culture inserts. After 48 h, cells were infected with influenza virus, and $2.5 \mathrm{~h}$ later were labeled with $\left[{ }^{35} \mathrm{~S}\right]$ methionine/cysteine for $2 \mathrm{~h}$. Apical or basolateral surface proteins were then labeled in separate culture inserts with sulfo-NHS-biotin. After cell lysis, biotinylated proteins were immunoprecipitated with streptavidin-agarose. To detect apical or basolateral surface expression of HA and of E-cadherin, the immunoprecipitates were subjected to autoradiography or to immunoblot analysis, respectively. The endogenous (dMAL) or the exogenous tagged-MAL levels in these cells were examined by immunoblot analysis with mAb 2E5 or 9E10, respectively. The results of a representative experiment are shown. (B) Quantitative analysis of the effect of MAL depletion on the polarized delivery of HA. The intensity of the apical and basolateral signal corresponding to radiolabeled HA were quantified. The mean values obtained in three independent replicates were expressed as percentages of radiolabeled HA on the apical (black bars) or basolateral surface (white bars). The SE was $<10 \%$ of the mean in all of the cases.

for endocytosed transferrin, suggesting that a high fraction of these elements is recycling endosomes. Most of these elements do not display a discernible coat although a significant fraction of them $(4.4 \pm 0.1 \%$ of MAL-RWKSS) exhibits a characteristic clathrin coat. In addition to low levels of MAL-RWKSS in the Golgi stacks and multivesicular bodies, $11.7 \pm 2.4 \%$ of MAL-RWKSS was in the plasma membrane, including clathrin-coated pits and buds. Finally, the observation that $1 \%$ of the total caveolin- 1 was present in $\sim 10 \%$ of the structures that were positive for MAL-RWKSS suggests that, although these two proteins are mostly in different GEM microdomains, they are expressed independently of each other, and have distinct requirements for becoming integrated into GEMs (Millán et al., 1997; Puertollano et al., 1999 b), they also probably intervene in GEM-mediated processes that require the simultaneous presence of both components. Consistent with a role for the endosome structures containing MAL in HA transport, a high percentage of those structures was also positive for newly synthesized HA en route to the plasma membrane. The influenza virus envelope possesses a high content of lipids enriched in GEM raft fractions (Scheiffele et al., 1999). The fact the viral particles budding from the plasma membrane were occasionally found to be positive for MAL might indicate that, once MAL is removed from the rafts, the virus builds its envelope with the same lipid rafts used for HA transport.

\section{Mutations Within the Carboxyl-Terminal RWKSS Sequence Render MAL Defective in Apical Transport of $\mathrm{HA}$}

Dilysine-based sorting signals can be inactivated by deletion of either one or two carboxyl-terminal amino acids, elongation with additional residues, or substitution of the basic amino acids (Jackson et al., 1990). The fact that the carboxy terminus of MAL ends with the RWKSS sequence resembling the dilysine-based consensus sequence prompted us to investigate its possible role in apical transport with the use of mutations known to affect the functionality of this type of signal but that do not affect the targeting of MAL to GEMs. HA acquires insolubility during biosynthetic transport to the plasma membrane, probably reflecting its incorporation into lipid rafts. This process starts taking place during transport through the Golgi (Skibbens et al., 1989) and does not require MAL expression (Puertollano et al., 1999a). However, the expression of MAL increases the levels of insoluble 
A

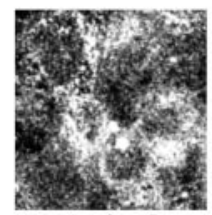

Apical
RWKSS

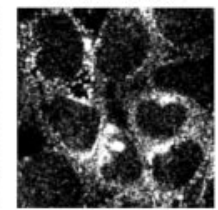

RWKSS

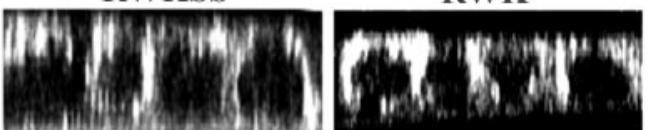

RWSSS

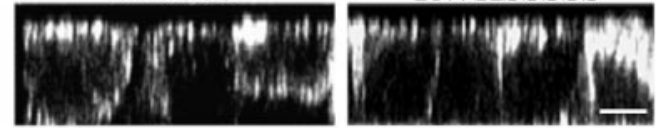

C

$$
0 \text { min }
$$
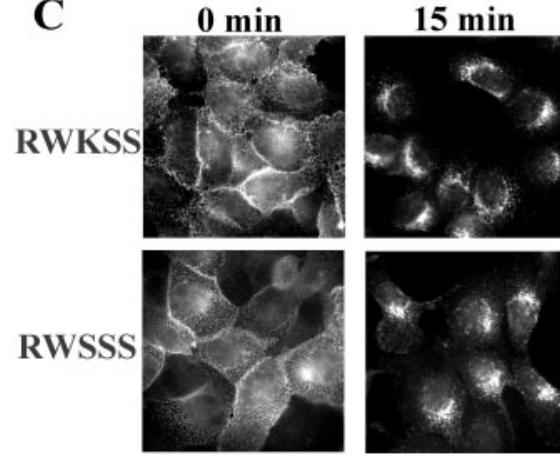

$30 \mathrm{~min}$
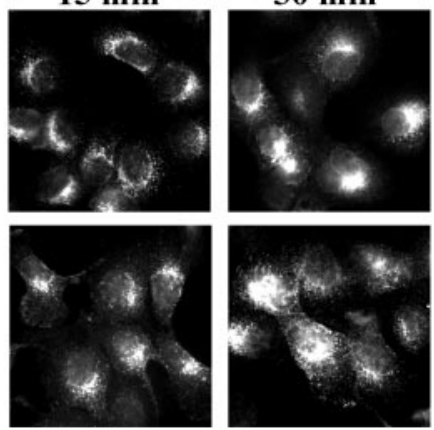

Figure 7. Confocal microscopy immunofluorescence analysis of the distribution of MAL-RWKSS, MAL-RWK, MAL-RWSSS, and MAL-RWKSSSSS in polarized MDCK cells. MDCK cells stably expressing the indicated MAL proteins were grown on tissue culture inserts, fixed, and processed for immunofluorescence microscopy with $\mathrm{mAb}$ 9E10. (A) Optical $\mathrm{x}-\mathrm{y}$ sections corresponding to the apical and the basal surfaces or to an equidistant intermediate plane of MDCK cells stably expressing MAL-RWKSS are shown. (B) The $x-z$ section of MDCK cells expressing either MAL-RWKSS, MAL-RWK, MAL-RWSSS, or MAL-RWKSSSSS is shown. (C) Comparative analysis of the endocytosis of MAL-RWKSS and MAL-RWSSS. Intact MDCK cells stably expressing either the MAL-RWKSS or MALRWSSS proteins tagged with an extracellular FLAG epitope were incubated with anti-FLAG antibodies for $1 \mathrm{~h}$ at $4^{\circ} \mathrm{C}$. After extensive washing to remove the excess of antibody, cells were incubated at $37^{\circ} \mathrm{C}$ for the indicated times to allow MAL internalization. Cells were then fixed, permeabilized, and incubated with fluorescent secondary antibodies to detect the MAL/FLAG molecules originally on the surface. Bars, $10 \mu \mathrm{m}$.

HA, probably by stabilization of HA in rafts during postGolgi transport (Puertollano et al., 1999a). Whereas all the mutants examined were able to produce an increase in the insolubility of HA as MAL-RWKSS does in cells with the endogenous MAL protein depleted, neither of them maintained the capacity to direct HA to the apical surface nor to prevent the missorting of HA to the basolateral membrane. This indicates a segregation between the two activities of MAL: the effect on HA insolubility probably depends on the overall MAL distribution, which is similar in all the MAL proteins analyzed, whereas the promotion of apical trans- port relies on the functioning of the dilysine-like RWKSS motif of MAL. Thus, the fact that we did not observe any effect on the insolubility of HA by mutation of the MAL dilysine-like motif could be explained by assuming that the passage of HA by the compartment where this sequence acts is rapid and transient and that the overall insolubility of HA depends to more extent on the predominant steady-state distribution of MAL.

\section{MAL Carboxyl-Terminal RWKSS Sequence, Dilysine-based Motifs, and Endosome Coats}

The loss of function of MAL-RWSSS, taken as representative of the MAL mutants with the dilysine-like sequence inactivated, in apical transport correlated with a twofold increase in the levels of MAL in tubular/vesicular structures containing a clathrin coat, and a diminished presence in the plasma membrane relative to the fully active MAL-RWKSS protein. It is of note that previous work indicates that the RWKSS pentapeptide can act as an ER-retrieval signal when transplanted to the CD4 molecule, used as a reporter protein (Puertollano and Alonso, 1999a). Even in the MAL molecule, the substitution of the serines in the RWKSS sequence by alanine (MAL-RWKAA) targets the molecule to the ER (Puertollano and Alonso, 1999a). This suggests that, although RWKSS does not work in MAL as an ER retrieval signal, this sequence is closely related to the dilysine-based signals involved in ER retrieval. COPI-coated vesicles have been implicated in retrograde transport of membrane proteins from the Golgi to the ER (Orci et al., 1997). Coatomer, a major protein complex of the COPI coat, interacts with dilysinebased ER retention signals (Cosson and Letourneur, 1994). In addition to its presence in the early secretory pathway, $\beta$-COP, a component of the COPI coat, has been identified in endosomes (Whitney et al., 1995; Aniento et al., 1996). This led to the suggestion that COPs might contribute to coat formation for endosomal membrane traffic, although it is not known whether dilysine-based motifs are involved in this process (Whitney et al., 1995; Aniento et al., 1996). In addition to the role of dilysine-based motifs as ER retrieval signals, the KKFF sequence has been demonstrated to be functional as an endocytosis signal (Itin et al., 1995). Thus, it is very likely that dilysine-based signals and COPI and/or COPIrelated complexes participate in sorting events other than that of retrieval of transmembrane proteins to the ER.

Endosomes have been found to assemble coats made of clathrin (Whitney et al., 1995; Stoorvogel et al., 1996). Endosome-associated clathrin-coated buds are smaller $(60 \mathrm{~nm})$ than the plasma membrane-derived clathrin-coated vesicles $(100 \mathrm{~nm})$ and have been postulated as serving as an exit pathway from endosomes (Stoorvogel et al., 1996). The increase observed in the levels of MAL-RWSSS in clathrinassociated endosomal structures and its parallel decrease on the plasma membrane was not caused by a more rapid endocytosis of MAL-RWSSS relative to that of MALRWKSS. The complex subcellular distribution of MAL in different compartments and the existence of other potential sorting signals, in addition to the dilysine-like motif, in its carboxy terminus that could have been also altered by the substitution of Lys -3 by Ser make it difficult to identify the precise step of MAL trafficking affected in MAL-RWSSS. One possibility is that the mutation present in MAL-RWSSS impairs recycling of MAL from endosomes to the TGN 

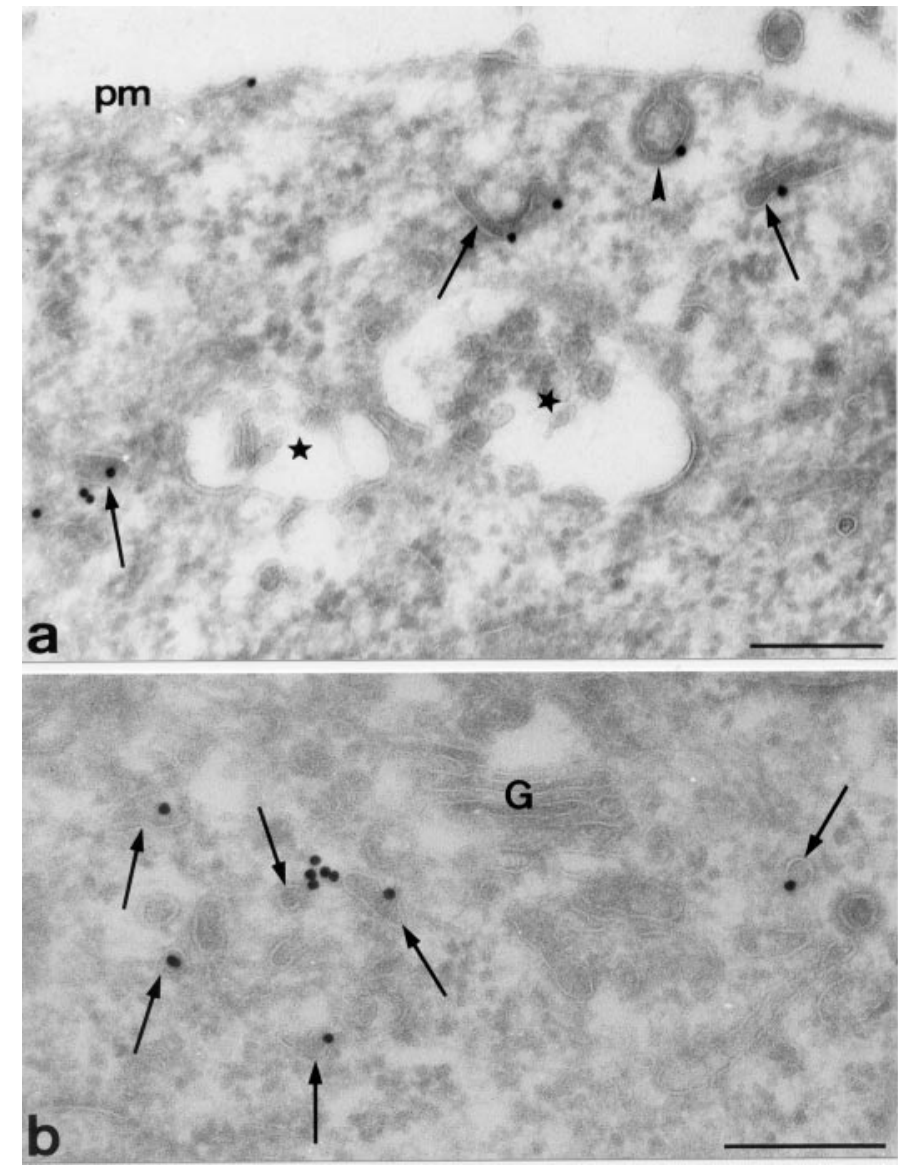

(Puertollano and Alonso, 1999b) and this causes a reduction in the number of MAL molecules ready to travel from the TGN to the cell surface. Alternatively, the differences between the distribution of MAL-RWKSS and MAL-RWSSS can be also simply explained assuming that MAL-RWSSS is defective in the exit from clathrin-containing endosomes for transport to the plasma membrane.

\section{Normal MAL Trafficking Is Necessary for Efficient Transport of $\mathrm{HA}$}

Most current models of polarized protein transport propose that, either in addition to or in place of the sorting that occurs in the TGN, the endocytic compartment of polarized cells contains sorting mechanisms (Matter and Mellman, 1994; van Ijzendoorn and Hoekstra, 1999). Sorting in the endocytic compartment is required to maintain the polarized phenotype despite the continuous traffic of proteins between both surfaces that, otherwise, would result in the mixing of the components of the apical and basolateral surface. Indeed, if newly synthesized proteins were delivered to the cell surface via a sorting endosome compartment, a separate polarized sorting station (i.e., the TGN) in the biosynthetic pathway would be unnecessary. Such pathways are known to exist because proteins such as the mannose-6-phosphate receptor are transferred from the Golgi to the endocytic pathway, and newly synthesized transferrin

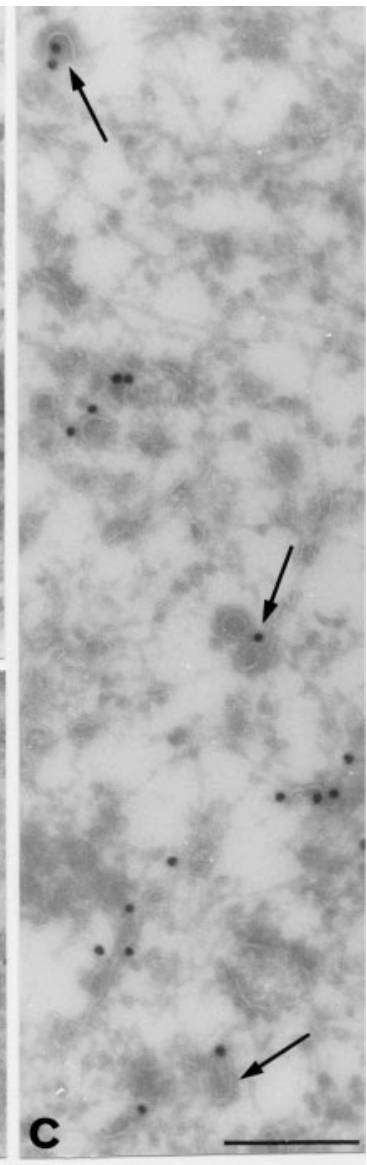

Figure 8. Immunoelectron microscopy analysis of the distribution of MAL-RWSSS in MDCK cells. Ultrathin cryosections of MDCK cells expressing MAL-RWSSS were immunolabeled for MAL with the use of anti-tag antibodies and $15-\mathrm{nm}$ protein-A gold particles. (a) MALRWSSS is detected in intracellular membranes (arrows) as well as the plasma membrane (pm) including a clathrin-coated bud (arrowhead). Note that multivesicular bodies (stars) are not immunoreactive. (b) Detail of the Golgi area where lateral vesicular profiles show specific immunolabeling (arrows). (c) Detail of the cytoplasm showing MAL-immunoreactive tubular/vesicular profiles. Note that some of them bear a clathrin-coat (arrows). pm, plasma membrane; G, Golgi stack. Bars, 200 nm.

and asialoglycoprotein receptors en route to the cell surface are detected in endosomes (Futter et al., 1995; Leitinger et al., 1995). More recently, a pIgR mutant that is selectively targeted to the apical surface has been detected in endosomes during biosynthetic transport (Orzech et al., 2000). Studies in epithelial MDCK cells have revealed that transferrin receptor and pIgR internalized from the apical and basolateral surfaces, respectively, meet at a common interconnected endosome compartment, the apical recycling/common endosome compartment (Apodaca et al., 1994; Odorizzi et al., 1996; Gibson et al., 1998), which includes 60-nm-diameter tubules with $\gamma$-adaptin and buds with clathrin lattices (Futter et al., 1998). In this compartment, internalized proteins are sorted and destined for the appropriate surface subdomain (Sheff et al., 1999). A recent report has shown that the apical recycling compartment and the common endosome compartment appear to differ in that internalized transferrin reaches the common endosome but not the apical recycling compartment, whereas internalized polymeric $\operatorname{IgA}$ is detected in both compartments (Leung et al., 2000). The morphology and size of the tubular/vesicular elements in which MAL-RWKSS was predominantly localized, the high level of colocalization of MAL-RWKSS with $\gamma$-adaptin, and the presence of clathrin lattices in some of these structures suggest that a fraction of MAL-RWKSS is in the apical recycling/ common endosome compartment. Most of the structures 


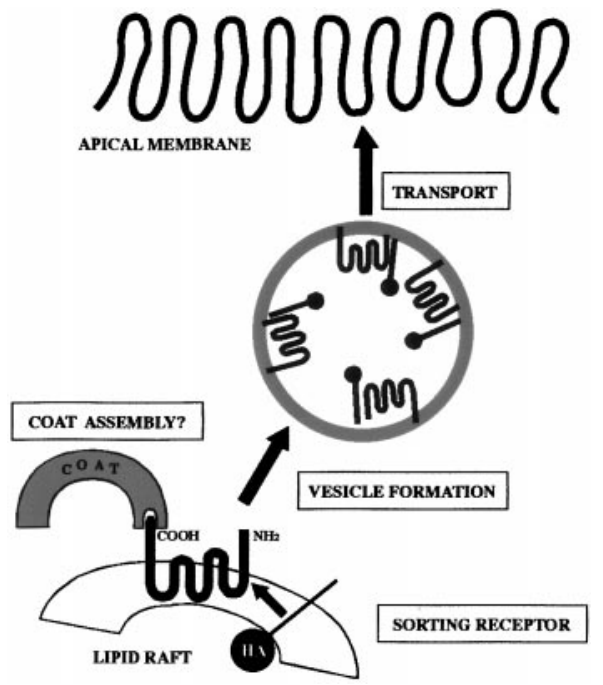

Figure 9. Schematic for the proposed role of MAL in apical transport.

positive for MAL were negative for the EEA1 sorting endosome marker, indicating that only a small fraction of MAL is in sorting endosomes. Moreover, the high level of colocalization of MAL with transferrin indicates that a large fraction of the tubulovesicular structures positive for MAL probably corresponds to the common endosome compartment (Leung et al., 2000). The high level of colocalization of HA in tubulovesicular structures containing MAL is consistent with that also newly synthesized HA traverses the endosome compartment en route to the cell surface. The impairment of MAL-RWSSS to rescue transport of HA to the apical plasma is likely a consequence of the trafficking defect in the MAL mutant responsible for the observed alterations in the steady-state intracellular distribution of MAL. Whether the dilysine-like signal of MAL is directly involved in transport of HA from endosomes to the cells surface or, alternatively, the lack of function of MAL-RWSSS in HA transport is an indirect consequence of the reduction in the number of MAL molecules available in the appropriate place (TGN or endosomes) to transporting HA to the plasma membrane is still an unsolved point.

\section{Model of MAL Function in Apical Transport}

The current knowledge of the function of MAL in apical transport can be integrated into the model that is schematically shown in Figure 9. According to this model, MAL has a role as a sorting receptor by which it stabilizes cargo proteins in GEMs, as occurs in HA (Puertollano et al., 1999a). This probably involves membrane-anchoring domain(s) in the cargo molecule (Lin et al., 1998; Scheiffele et al., 1998). A role for MAL in formation of transport vesicles has also been proposed, based on its capacity to induce massive vesiculation of GEMs giving rise to vesicles (Puertollano et al., 1997) that are different from the caveolae-like vesicles induced by caveolin-1 with the use of the same expression system (Li et al., 1996). The stabilization of cargo HA molecules in lipid rafts (Puertollano et al., 1999a) and the vesiculation capacity of MAL might be related to the presence in its carboxy terminus (Phe-Ser-Leu-Ile-Arg-Trp-Lys-Ser-Ser) of sequences resembling tyrosine- (Phe-Ser-Leu-Ile), dileucine(Leu-Ile), diaromate- (Phe-Ser-Leu-Ile-Arg-Trp), and dilysine-based (Arg-Trp-Lys-Ser-Ser) sorting motifs that are known to direct the assembly of vesicle coats (Trowbridge et al., 1993; Sandoval and Bakke, 1994; Marks et al., 1997). The polymerization of coat proteins directed by the cytoplasmic carboxyl-terminal sequences of MAL might stabilize cargo molecules in rafts, probably involving transient MAL aggregation, likewise external cross-linking of surface proteins with antibodies stabilizes proteins in lipid rafts (Harder et al., 1998). Consistent with a role for the carboxy terminus of MAL in transport, our observation that MAL-RWSSS accumulates in endosome elements with clathrin and is diminished in the plasma membrane indicates that the mutation within the dilysine-like RWKSS sequence impairs normal MAL trafficking. Similarly, the other sequences in the MAL carboxy terminus resembling sorting motifs might be involved in other steps of MAL trafficking and, thus, regulate transport of cargo molecules to the apical surface (Puertollano and Alonso, 1999b).

\section{ACKNOWLEDGMENTS}

We thank Dr. Carlos Sánchez for help with the use of the confocal microscopy. R.P. and A.B. are recipients of predoctoral fellowships from the Comunidad de Madrid. J.A.M.-M. is supported by a Marie Curie Return Fellowship from the European Commission. This work was supported by grants from the Dirección General de Enseñanza Superior (PM99-0092 and PM99-137) and the Comunidad de Madrid (08.3/0025/2000). An institutional grant from the Fundación Ramón Areces to Centro de Biología Molecular Severo Ochoa is also acknowledged.

\section{REFERENCES}

Alonso, M.A., and Weissman, S.M. (1987). cDNA cloning and sequence of MAL, a hydrophobic protein associated with human T-cell differentiation. Proc. Natl. Acad. Sci. USA 84, 1997-2001.

Anderson, R.G.W. (1998). The caveolae membrane system. Annu. Rev. Biochem. 67, 199-225.

Aniento, F., Gu, F., Parton, R.G., and Gruenberg, J. (1996). An endosomal $\beta$-COP is involved in the $\mathrm{pH}$-dependent formation of transport vesicles destined for late endosomes. J. Cell Biol. 133, $29-41$.

Apodaca, G., Katz, L.A., and Mostov, K.E. (1994). Receptor-mediated transcytosis of IgA in MDCK cells is via apical recycling endosomes. J. Cell Biol. 125, 67-86.

Brown, D.A., and Rose, J.K. (1992). Sorting of GPI-anchored proteins to glycolipid-enriched membrane subdomains during transport to the apical cell surface. Cell 68, 533-544.

Cheong, K.H., Zacchetti, D. Schneeberger, E.E., and Simons, K. (1999). VIP17/MAL, a lipid raft-associated protein, is involved in apical transport in MDCK cells. Proc. Natl. Acad. Sci. USA 96, 6241-6248.

Cosson, P., and Letourneur, F. (1994). Coatomer interaction with dilysine endoplasmic reticulum retention motifs. Science 263, 16291631.

Dell'Angelica, E.C., Mullins, C., and Bonifacino, J.S. (1999). AP-4, a novel protein complex related to clathrin adaptors. J. Biol. Chem. $274,7278-7285$. 
Dupree, P., Parton, R.G., Raposo, G., Kurzchalia, T.V., and Simons, K. (1993). Caveolae and sorting in the trans-Golgi network of epithelial cells. EMBO J. 12, 1597-1605.

Friedrichson, T., and Kurzchalia, T.V. (1998). Microdomains of GPIanchored proteins in living cells revealed by crosslinking. Nature 394, 802-805.

Futter, C.E., Connolly, C.N., Cutler, D.F., and Hopkins, C.R. (1995). Newly synthesized transferrin receptors can be detected in the endosome before they appear on the cell surface. J. Biol. Chem. 270, 10999-11003.

Futter, C.E., Gibson, A., Allchin, E.H., Maxwell, S., Ruddock, L.J., Odorizzi, G., Domingo, D., Trowbridge, I.S., and Hopkins, C.R. (1998). In polarized MDCK cells basolateral vesicles arise from clathrin- $\gamma$-adaptin-coated domains on endosomal tubules. J. Cell Biol. 141, 611-623.

Gagescu, R., Demaurex, N., Parton, R.G., Hunziker, W., Huber, L.A., and Gruenberg, J. (2000). The recycling endosome of Madin-Darby canine kidney cells is a mildly acidic compartment rich in raft components. Mol. Biol. Cell 11, 2775-2791.

Gibson, A., Futter, C.E., Maxwell, S., Allchin, E.H., Shipman, M., Kraehenbuhl, J.-P., Domingo, D., Odorizzi, G., Trowbridge, I.S., and Hopkins, C.R. (1998). Sorting mechanisms regulating membrane protein traffic in the apical transcytotic pathway of polarized MDCK cells. J. Cell Biol. 143, 81-94.

Gruenberg, J., and Maxfield, F.R. (1995). Membrane transport in the endocytic pathway. Curr. Opin. Cell Biol. 7, 552-563.

Harder, T., Scheiffele, P., Verkade, P., and Simons, K. (1998). Lipid domain structure of the plasma membrane revealed by patching of membrane components. J. Cell Biol. 141, 929-942.

Hirst, J., Bright, N.A., Rous, B., and Robinson, M.S. (1999). Characterization of a fourth adaptor-related protein complex. Mol. Biol. Cell 10, 2787-2802.

Itin, C., Kappeler, F., Linstedt, A.D., and Hauri, H.-P. (1995). A novel endocytosis signal related to the KKXX ER-retrieval signal. EMBO J. 14, 220-2256.

Jackson, M.R., Nilsson, T., and Peterson, P.A. (1990). Identification of a consensus motif for retention of transmembrane proteins in the endoplasmic reticulum. EMBO J. 9, 3153-3162.

Jackson, M.R., Nilsson, T., and Peterson, P.A. (1993). Retrieval of transmembrane proteins to the endoplasmic reticulum. J. Cell Biol. 121, 317-333.

Keller, P., and Simons, K. (1998). Cholesterol is required for surface transport of influenza virus hemagglutinin. J. Cell Biol. 140, 13571367.

Kim, T., Fiedler, K., Madison, D.L.,. Krueger, W.H., and Pfeiffer, S.E. (1995). Cloning and characterization of MVP17: a developmentally regulated myelin protein in oligodendrocytes. J. Neurosci. Res. 42, 413-422.

Le Bivic, A., Sambuy, Y., Mostov, K., and Rodriguez-Boulan, E. (1990). Vectorial targeting of an endogenous apical membrane sialoglycoprotein and uvomorulin in MDCK cells. J. Cell Biol. 110, 1533-1539.

Le Borgne, R., and Hoflack, B. (1998). Mechanism of protein sorting and coat assembly: insights from the clathrin-coated vesicle pathway. Curr. Opin. Cell Biol. 10, 499-503.

Leitinger, B.A., Hille-Rehfeld, A., and Spiess, M. (1995). Biosynthetic transport of the asialoglycoprotein receptor H1 to the cell surface occurs via endosomes. Proc. Natl. Acad. Sci. USA 92, 10109-10113.

Leung, S.-M., Ruiz, W.G., and Apodaca, G. (2000). Sorting of membrane and fluid at the apical pole of polarized Madin-Darby canine kidney cells. Mol. Biol. Cell 11, 2131-2150.
Li, S., Song, K.S., Koh, S.S., Kikuchi, A., and Lisanti, M.P. (1996). Baculovirus-based expression of mammalian caveolin in Sf21 insect cells. J. Biol. Chem. 271, 28647-28654.

Lin, S., Naim, H.Y., Rodriguez, A.C., and Roth, M.G. (1998). Mutations in the middle of the transmembrane domain reverse the polarity of transport of the influenza virus hemagglutinin in MDCK epithelial cells. J. Cell Biol. 142, 51-57.

Marks, M.S., Ohno, H., Kirchhausen, T., and Bonifacino, J. (1997). Protein sorting by tyrosine-based signals: adapting to the Ys and wherefores. Trends Cell Biol. 7, 124-128.

Martín-Belmonte, F., Kremer, L., Albar, J.P., Marazuela, M., and Alonso, M.A. (1998). Expression of the MAL gene in the thyroid: the MAL proteolipid, a component of glycolipid-enriched membranes, is apically distributed in thyroid follicles. Endocrinology 139, 20772084.

Martín-Belmonte, F., Puertollano, R., Millán, J., and Alonso, M.A. (2000). The MAL proteolipid is necessary for the overall apical delivery of membrane proteins in the polarized epithelial MadinDarby canine kidney and Fischer Rat Thyroid cell lines. Mol. Biol. Cell 11, 2033-2045.

Martínez-Menárguez, J.A., Geuze, H.J., Slot, J.W., and Klumperman, J. (1999). Vesicular tubular clusters between the ER and the Golgi mediate concentration of soluble secretory proteins by exclusion from COPI-coated vesicles. Cell 98, 81-90.

Matter, K., and Mellman, I. (1994). Mechanisms of cell polarity: sorting and transport in epithelial cells. Curr. Opin. Cell Biol. 6, $545-554$.

Millán, J., and Alonso, M.A. (1998). MAL, a novel integral membrane protein of human T lymphocytes, associates with glycosylphosphatidylinositol-anchored proteins and Src-like tyrosine kinases. Eur. J. Immunol. 28, 3675-3684.

Millán, J., Puertollano, R., Fan, L., and Alonso, M.A. (1997). Caveolin and MAL, two protein components of internal detergent-insoluble membranes, are in distinct lipid microenvironments in MDCK cells. Biochem. Biophys. Res. Commun. 233, 707-712.

Odorizzi, G., Pearse, A. Domingo, D., Trowbridge, I.S., and Hopkins, C.R. (1996). Apical and basolateral endosomes of MDCK cells are interconnected and contain a polarized sorting mechanism. J. Cell Biol. 135, 139-152.

Orci, L., Stamnes, M., Ravazzola, M., Amherdt, M., Perrelet, A., Söllner, T.S., and Rothman, J.E. (1997). Bidirectional transport by distinct populations of COPI-coated vesicles. Cell 90, 335-349.

Orzech, E., Cohen, S., Weiss, A., and Aroeti, B. (2000). Interactions between the exocytic and endocytic pathways in polarized MadinDarby canine kidney cells. J. Biol. Chem. 275, 15207-15219.

Puertollano, R., and Alonso, M.A. (1998). A short peptide motif at the carboxyl terminus is required for incorporation of the integral membrane MAL protein to glycolipid-enriched membranes. J. Biol. Chem. 233, 12740-12745.

Puertollano, R., and Alonso, M.A. (1999a). Substitution of the two carboxyl-terminal serines by alanine causes retention of MAL, a component of the apical sorting machinery, in the endoplasmic reticulum. Biochem. Biophys. Res. Commun. 260, 188-192.

Puertollano, R., and Alonso, M.A. (1999b). MAL, an integral element of the apical sorting machinery, is an itinerant protein that cycles between the trans-Golgi network and the plasma membrane. Mol. Biol. Cell 10, 3435-3447.

Puertollano, R., Li, S., Lisanti, M.P., and Alonso, M.A. (1997). Recombinant expression of the MAL proteolipid, a component of glycolipid-enriched membrane microdomains, induces the formation of vesicular structures in insect cells. J. Biol. Chem. 272, 1831118315. 
Puertollano, R., Martín-Belmonte, F., Millán, J., de Marco, M.C., Albar, J.P., Kremer, L., and Alonso, M.A. (1999a). The MAL proteolipid is necessary for normal apical transport and accurate sorting of the influenza virus hemagglutinin in Madin-Darby canine kidney cells. J. Cell Biol. 145, 141-145.

Puertollano, R., Menéndez, M., and Alonso, M.A. (1999b). Incorporation of MAL, an integral protein element of the machinery for the glycolipid and cholesterol-mediated apical pathway of transport, into artificial membranes requires neither of these lipid species. Biochem. Biophys. Res. Commun. 266, 330-333.

Robinson, M.S. (1990). Cloning and expression of $\gamma$-adaptin, a component of clathrin-coated vesicles associated with the Golgi apparatus. J. Cell Biol. 111, 2319-2316.

Sandoval, I.V., and Bakke, O. (1994). Targeting of membrane proteins to endosomes and lysosomes. Trends Cell Biol. 4, 292-297.

Scheiffele, P., Rietveld, A., Wilk, T., and Simons, K. (1999). Influenza viruses select ordered lipid domains during budding from the plasma membrane. J. Biol. Chem. 274, 2038-2044.

Scheiffele, P., Roth, M.G., and Simons, K. (1998). Interaction of influenza virus hemagglutinin with sphingolipid-cholesterol membrane domains via its transmembrane domain. EMBO J. 16, 55015508 .

Sheff, D.R., Daro, E.A., Hull, M., and Mellman, I. (1999). The receptor recycling pathway contains two distinct populations of early endosomes with different sorting functions. J. Cell Biol. 145, 123139.

Shin, J., Dunbrack, R.L., Lee, S., and Strominger, J.L. (1991). Signals for retention of transmembrane proteins in the endoplasmic reticulum studied with CD4 truncation mutants. Proc. Natl. Acad. Sci. USA $88,1918-192$.

Simons, K., and Ikonen, E. (1997). Functional rafts in cell membranes. Nature 387, 569-572.

Simons, K., and Wandinger-Ness, A. (1990). Polarized sorting in epithelia. Cell 62, 207-210.

Skibbens, J.E., Roth, M.G., and Matlin, K.S. (1989). Differential extractability of influenza virus hemagglutinin during intracellular transport in polarized epithelial cells and nonpolar fibroblasts. J. Cell Biol. 108, 821-832.

Slot, J.W., Geuze, H.J., Gigengack, S., Lienhard, G.E., and James, J.E. (1991). Immuno-localization of the insulin regulatable glucose transporter in brown adipose tissue of the rat. J. Cell Biol. 113, 123-135.

Smart, E.J., Graf, G.A., McNiven, M.A., Sessa, W.C., Engelman, J.A., Scherer, P.E., Okamoto, T., and Lisanti, M.P. (1999). Caveolins, liquid-ordered domains, and signal transduction. Mol. Cell. Biol. 19, 7289-7304.

Stoorvogel, W., Oorschot, V., and Geuze, H.J. (1996). A novel class of clathrin-coated vesicles budding from endosomes. J. Cell Biol. $132,21-33$.

Traub, L.M., and Kornfeld, S. (1997). The trans-Golgi network: a late secretory station. Curr. Opin. Cell Biol. 9, 527-533.

Trowbridge, I.S., Collawn, J.F., and Hopkins, C.R. (1993). Signaldependent membrane protein trafficking in the endocytic pathway. Annu. Rev. Cell Biol. 9, 129-161.

van Ijzendoorn, S.C.D., and Hoekstra, D. (1999). The subapical compartment: a novel sorting center?. Trends Cell Biol. 9, 144-149.

Varma, R., and Mayor, S. (1998). GPI-anchored proteins are organized in submicron domains at the cell surface. Nature 394, 798801.

Whitney, J.A., Gomez, M., Sheff, D., Kreis, T.E., and Mellman, I. (1995). Cytoplasmic coat proteins involved in endosome function. Cell 83, 703-711.

Wilson, J.M., de Hoop, M., Zorzi, N., Toh, B.-H., Dotti, C.G., and Parton, R.G. (2000). EEA1, a tethering protein of the early sorting endosome, shows a polarized distribution in hippocampal neurons, epithelial cells, and fibroblasts. Mol. Biol. Cell 11, 2657-2671.

Yamashiro, D.J., Tycko, B., Fluss, S.R., and Maxfield, F.R. (1984). Segregation of transferrin to a mildy acidic $(\mathrm{pH}$ 6.5) para-Golgi compartment in the recycling pathway. Cell 37, 789-800.

Zacchetti, D., Peranen, J., Murata, M., Fiedler, K., and Simons, K. (1995). VIP17/MAL, a proteolipid in apical transport vesicles. FEBS Lett. 377, 465-469. 